NBSIR 75-927

\title{
The National Measurement System for Surface Finish
}

Russell D. Young

Institute for Basic Standards National Bureau of Standards

Washington, D. C. 20234

\section{March 1976}

Final

Issued July 1976

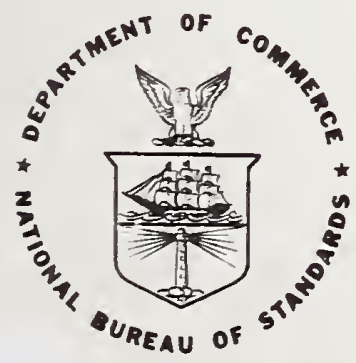

Qc 100 5. DEPARTMENT OF COMMERCE

. U 56 IONAL BUREAU OF STANDARDS

* 75.927

1976 


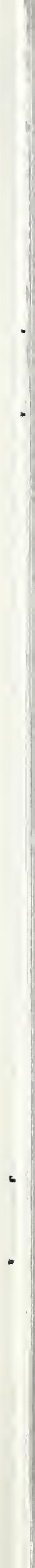




\section{THE NATIONAL MEASUREMENT SYSTEM FOR SURFACE FINISH}

Russell D. Young

Institute for Basic Standards

National Bureau of Standards

Washington, D. C. 20234

March 1976

Final

Issued July 1976

U.S. DEPARTMENT OF COMMERCE, Elliot L. Richardson, Secretary Edward O. Vetter, Under Secretary

Dr. Betsy Ancker-Johnson, Assistant Secretary for Science and Technology

NATIONAL BUREAU OF STANDARDS, Ernest Ambler, Acting Director 
.

.

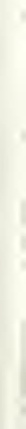


EXECUTIVE SUMMARY

1. INTRODUCTION

2. STRUCTURE OF THE MEASUREMENT SYSTEM

2.1 Conceptual System

2.2 Basic Technical Infrastructure.

2.2.1 Documentary Specification System

2.2.1.1 Standardization Institutions

2.2.1.2 Survey of Documentary Standards

2.2.2 Instrumentation System

2.2.2.1 Measurement Tools and Techniques

2.2.2.2 The Instrumentation Industry

2.2.3 Reference Data

2.2.4 Reference Material

2.2.5 Science and People

2.3 Realized Measurement Capabilities . . . . . . . . . . . . .

2.4 Dissemination and Enforcement Network $\ldots$

2.4.1 Central Standards Authorities . . . . . . . . . . . . .

2.4.2 State and Local Offices of Weights and Measures . . . . . . . .

2.4.3 Standards and Testing Laboratories and Services ..........

2.4.4 Regulatory Agencies....................

2.5 Direct Measurement Transactions Matrix . . . . . . . . . . . . .

3. IMPACT, STATUS AND TRENDS OF MEASUREMENT SYSTEM . . . . . . . . . . .

3.1 Impact of Measurements......

3.1.1 Functional, Technological and Scientific Applications

3.1.1.1 Dairy and Food Industry Storage and Distribution Containers
3.1.1.2 The Surface Finish of Surgical Implants .........

3.1.1.3 Gravure Illustrations

3.1.1.4 Surface Finish Requirements for Automobile Motors, Transmissions and Brake Drums

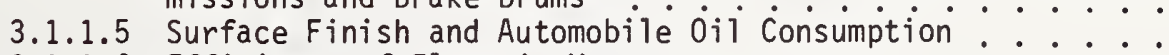

3.1.1.6 Efficiency of Electric Motors . . . . . . . .

3.1.1.7 Shaft and Radial Lip Seal Surface Finish

3.1.1.8 Paintability of Surfaces - New Powder Coatings

3.1.1.9 Electroforming - Duplication of Highly Finished Surface :

3.1.1.10 Surface Requirement in the Electronics Industry ...

3.1.1.11 Summary of Measurement Needs

3.1.1.12 Distribution of Surface Finish instrumentation

3.1.1.13 Measurement Needs in High Technology Industries $: \dot{0}^{\circ}$

3.1.2 Economic Impacts -- Costs and Benefits . . . . . . . . . . . .

3.1.3 Social, Human, Person-on-the-street Impacts . . . . . . . .

3.2 Status and Trends of the System .................

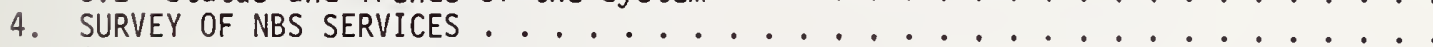

4.1 The Past

4.2 The Present -- Scope of NBS Services

4.2.1 Description of NBS Services

4.2.2 Users of NBS Services

4.2.3 Alternate Sources

4.2.4 Funding Sources for $\mathrm{NBS}^{\circ}$ Services . . . . . . . . . . . .

4.2.5 Mechanism for Supplying Services ..............

4.3 Impact of NBS Services

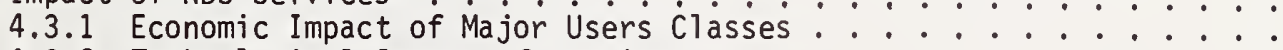

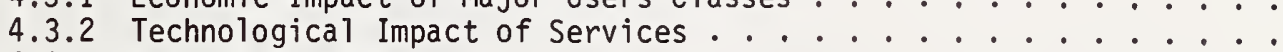

4.3.3 Pay-off from Changes in NBS Services .............

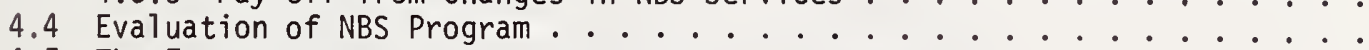

4.5 The Future .. . . . . . . . . . . . . . . . . .

4.5.1 Driving Force of NBS Programs . . . . . . . . . . .

4.5.2 Alternative NBS Responses to Surface Measurement Needs . . . . .

5. SUMMARY AND CONCLUSIONS 
Appendix A. METHOLOLOGY OF THE STUdY . . . . . . . . . . . . . .

A. 1 Literature Survey 34

A.2 List of People Consulted in Preparing This National Measurement

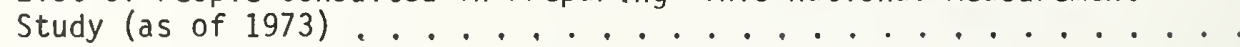

A. 3 List of People Contacted by Phone, at Meetings, etc. . . . . .

A.4 Typical Correspondance on Industrial Surface Finish . . . . . . . Appendix B. SUMMARY OF BACKGROUND DOCUMENTS . . . . . . . . . . . . . .

B.1 ASA B46.1-1962 Standard for Surface Finish . . . . . . . . . . . . . 34 $36-38$

B.2 Surface Finish, Friction and Wear: The Need for More than One

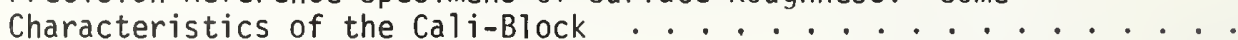

B.4 Calibration Report - Precision Reference Specimen of Surface

B.5 The Public Health Significance of Surface Measurements . . . . .

B.6 Eight Techniques for the Optical Measurement of Surface Roughness . .

B.7 Surface Microtopography . . . . . . . . . . . . . . .

B.8 The Topografiner: An Instrument for Measuring Surface Microtopography ... . . . . . . . . . . . . .

B.9 Evaluation, Revision and Application of the NBS Stylus/Computer 
Figure 1: Pictorial representation of roughness, waviness, lay and flaws

Figure 2: Surface finish measurement system infrastructure

Figure 3: Surface finish calibration flow chart 6

Figure 4: Typical stylus instrument 9

Figure 5: Precision reference specimens of roughness 9

Figure 6: Surface finish measurement capability vs time $(1930$ - 1980)

Figure 7: Calibration accuracy vs magnitude of surface roughness

Figure 8: Calibration accuracy vs height of thin film steps

Figure 9: Synthetic rubber friction theory 20

Figure 10: Cost comparison charts:

a) turned surfaces

b) face milled surface

Figure 11: NBS information and calibration Input-0utput chart

\section{LIST OF TABLES}

Table 1: Subcommittee chairmanships for ISO/TC-57

Table 2: List of recommended ISO surface standards (published and under review 1974)

Table 3: U.S. and foreign manufacturers of instrumentation for measuring surface roughness

Table 4: Surface roughness of automobile motor production parts in microinches $A A$

Table 5: Surface roughness of automobile drive-chain components in microinches $A A$

Table 6: Direct measurement transactions matrix 16

Table 7: Dependence of seal torque on surface roughness 20

Table 8: Cost of individual seals in U.S. manufactured cars and estimated total yearly cost

Table 9: Measurement improvement impact matrix

Table 10: Distribution of surface finish instrumentation

Table 11: Economic dimensions of impact areas in surface finish measurement in the metalworking industry

Table 12: Table of surface measurement needs related to some present day national issues 


\author{
Russel1 D. Young
}

National Bureau of Standards

\section{EXECUTIVE SUMMARY}

Surface finish measurements involve the outside surfaces of products, the part which is most evident to the user and which is frequently responsible for the quality of its performance. The average consumer can visually detect less than one millionth of an inch of surface roughness in a highly finished chrome plated surface. The reliability of clock motors, the performance of switches, the effectiveness of razor blades, the safety of a wheel bearing, a 11 of these depend on careful measurements of manufactured surfaces.

The National Measurement System for surface finish consists of the standards, the measurement techniques and procedures, the personnel, and the equipment through which surface finish measurements are conducted in the United States. The purpose of this study was to determine as quantitatively as possible the structure, vitality, integrity and future requirements of this measurement system. The study was initiated by a literature search, followed by visits to instrument manufacturers, industrial laboratories and academic institutions.

Each of the hundreds of metalworking industries has a special surface finish requirement. The highly polished pipes and tanks of the dairy, food and hospital supply industries permit rapid sanitation inspection. Quality of magazine illustrations depends upon the surface finish of gravure plates and cylinders. Automotive safety and reliability is related to the surface finish of hundreds of bearing, seals, brake drums, valves, cylinders, etc. The lifetime of surgical implants is directly related to their surface finish. Military applications abound. The list is endless. Yet, each application requires different surface micro-features. The most important conclusion of this study was that NBS should develop measuring procedures and methods for analyzing surface profiles so that each metalworking industry can properly inspect its surfaces according to its needs.

The second most important measurement need is for instrumentation capable of measuring new, high technology surfaces such as integrated circuits, computer discs and drums, surgical implants and precision bearings. New molecular electronic devices require surfaces which are smooth on the atomic scale. A third important need is for on-line surface finish measurement in manufacturing processes.

NBS calibrates precision reference specimens of surface roughness (carefully manufactured rough surfaces) according to the voluntary American National Standard B46.1. These specimens provide calibration users with a readily available physical standard to check their instruments. The integrity of the measurement system is maintained by national and international intercomparisons and by direct calibration of users ${ }^{\prime}$ standards. There are no regulatory agencies in surface finish. NBS also calibrates thin film steps for the microcircuit industry. Since both thin film steps and surface finish measurements are basically length measurements, NBS bases these calibrations on the defined unit of length through interferometry.

The information gathered in this study has already provided a solid basis for management decisions within NBS with regard to the distribution of the very limited resources in the surface program (2 1/3 man years; $\$ 84 \mathrm{~K}$ of NBS funds). For example, first priority has been given to a new calibration facility which includes computer analysis of surface profiles. Second priority is assigned to the development of new, high resolution instrumentation. Work with standards committees also has a high priority.

The study revealed a broadly based need for research leading to an understanding of the relationship between the surface finish and the function of a part. Such a study cannot be underwritten by instrument manufacturers since the 25,000 instruments now in use are very long lived. Yearly sales of the largest U.S. instrument manufacturer amount to only $\$ 1$ million per year. The metalworking industry spends $\$ 54$ million yearly in making surface finish measurements on products whose market value exceeds $\$ 40$ billion. Yet this effort is thinly spread over hundreds of industries, so that little 
reported research is done. These circumstances have resulted in stagnation in U.S. surface programs relative to governmentsupported foreign research. NBS is now able to provide measurements and instrumentation to those who wish to pursue such programs in the U.S. Several small cooperative efforts with industry and a university are now underway. 


\section{INTRODUCTION}

A typical consumer can visually detect a barely measurable one half of a millionth an inch in the surface finish of a chrome-plated toaster.

From morning till night we use, enjoy, seek out, depend upon, and excoriate highly finished surfaces. We awake to an inexpensive alarm clock whose motor bearings are finished to about one microinch, shave with a razor blade which has highly characterized, ul tra-smooth surfaces; we turn on the electric stove with switches whose contacts are specially prepared surfaces and use a waffle iron whose chrome plated surfaces rely on very highly finished steel from rolling mills. Many of the foods we eat are manufactured and transported in stainless steel containers with mirror finishes. Almost all household appliances have one or two surface finish requirements; some, such as the washer, dishwasher, electric iron, blender, freezer, refrigerator, etc., have many requirements. It staggers the imagination to realize that tin can surfaces are smooth to 10 microinches to economize on the use of tin.

The ubiquitous automobile is a product with hundreds of surface finish requirements, some very stringent. A selected list of 26 surface finish requirements for automobile motors and 17 requirements for automatic transmissions is given below. Early component failure sometimes results if a surface fails to meet inspection requirements, and some failures can involve serious safety hazards.

Hospital and surgical surfaces are highly finished to meet rigid sanitation and sterilization requirements. Surgical implants, such as hip joints, are polished to a finish which is beyond the measurement capability of the finest instrument today. Eyeglasses and contact lenses are highly finished to avoid confusing and annoying light scattering. Undesirable effects sometimes result when highly finished windshields, chrome, and painted surfaces generate annoying or dangerous glare. The list is endless. Indeed, a very large fraction of the products comprising the Gross National Product are in some way dependent on highly finished surfaces. To achieve functionally adequate surfaces and/or cosmetic acceptability, manufacturers employ sensitive, precise surface finish measurements throughout their production processes.

To accomplish the necessary measurements, U.S. manufacturers employ over
25,000 instruments, thousands of man-years of work and considerable R \& D. Our technological society is such that a ball bearing made in Germany or in San Francisco must meet specifications and fit mating components in Detroit and Tokyo. Without accurate and reproduceable surface finish measurements this compatibility could not be achieved. Indeed, a host of measurements require the existence of an accurate, hierarchical, consistent measurement system.

In 1972, the National Bureau of Standards (NBS) undertook a full scale evaluation of all components of the National Measurement System to determine as quantitatively as possible the structure, vitality, integrity and future requirements of each component. The surface finish measurement system was identified as one such component. Much of what follows will focus on the what, where, why, when and how of surface finish measurements, the infrastructure of the surface finish measurement system, and the role of NBS in this system.

The National Measurement System for Surface Finish consists of documentary and artifact standards, measurement techniques and procedures, personnel, and equipment through which all surface finish measurements are conducted. The purpose of this study is to 1) develop and test a model of the National Measurement System infrastructure, 2) identify the industries and social groups upon which the measurement system impacts, 3) insofar as possible, determine the economic dimensions of the impact areas, 4) examine critically the quality of the present measurement system in terms of present and projected needs, 5) make specific recommendations for future NBS programs, and 6) develop reprogramming guidelines so that NBS can more effectively accept its National Measurement System responsibilities.

In carrying out this study, 1) the literature was searched and evaluated, 2) visits were made to standards laboratories, instrument manufactures, industrial users and academic institutions, 3) users were consulted by letter and phone, and 4) technical meetings were used to initiate dialogues on measurement deficiencies. The findings were digested, organized and are presented herein. 


\section{STRUCTURE OF THE MEASUREMENT SYSTEM}

\subsection{Conceptual System}

Surface finish (roughness, texture, etc.) is a major branch of surface technology concerned with the micro-geometry and microtopography of the surfaces of solids. In manufacturing physical objects, the process of generating the nominal (intended) surface is always imperfect. The four major deviations from the nominal surface are called roughness, waviness, 1 ay and flaws. Roughness consists of the finer irregularities in the surface texture including those irregularities which result from the inherent action of the production process. Waviness is the widely spaced component of the surface texture and is usually eliminated from the surface finish measurement process by electrical or mechanical filters. Lay is the direction of the predominant surface pattern, ordinarily determined by the production method used. Flaws are irregularities which occur at one place or at relatively infrequent intervals. These concepts are depicted in figure 1. The present report is concerned chiefly with roughness, which is a quantitative description of surface finish. Standards have not been established for waviness and lay. Traditionally, the roughness is characterized by the average deviation of the profile of the true surface from the nominal surface (Arithmetical Average roughness $(A A))$. Almost all manufactured goods have some surface finish requirement, whether functional or cosmetic. In the extreme case, some optical components require that surfaces have roughness no greater than a few atomic layers (less than one ten millionth of an inch).

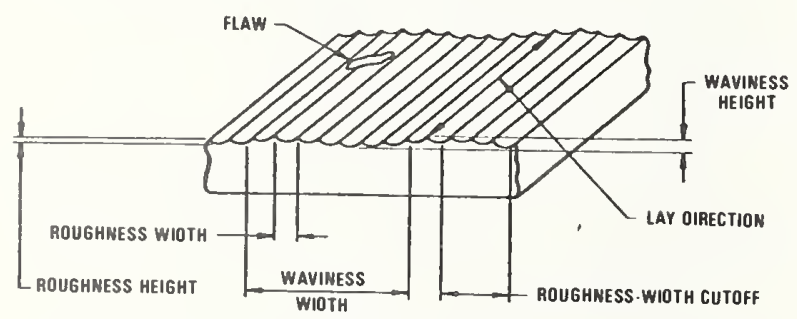

Figure 1: Pictorial representation of roughness, waviness, lay and flaws in a manufactured surface.

The formal definition of Arithmetic Average Roughness $(A A)$ is:

$$
A A=\frac{1}{L} \int_{0}^{L}|y| d x
$$

where $L$ is the distance along the surface corresponding to the greatest spacing of repetitive surface irregularities to be included in the roughness measurement (roughness width cutoff), $y$ is the vertical displacement of the actual surface from nominal and $x$ is the distance along the nominal surface.

The metric system of units will be adopted as soon as a new standard has been completed and accepted. Until then, surface roughness (in the U.S.A.) will continue to be given in microinches $A A$. Under the new standard, roughness will be in micrometers with NBS calibrations derived from interferometric measurements which relate $A A$ quite directly to the defined unit of length: the wavelength of certain light sources.

The physical reference standards used to calibrate surface roughness instrumentation and to disseminate these calibrations is called a Precision Reference Specimen. While there are many types, these specimens consist of finely ruled parallel lines on flat hard surfaces such as glass and electrodeposited nickel. They are a few tens of square $\mathrm{cm}$ in area and are believed to be extremely stable, suffering only from wear or accidental damage. They are periodically calibrated by NBS for various types of standards laboratories who in turn employ them in secondary calibrations of instruments and other Precision Reference Specimens.

\subsection{Basic Technical Infrastructure}

Figure 2 is a hierarchically stratified block diagram of the surface finish measurement system insofar as NBS can determine it. The numbered blocks are interconnected with lines which are coded (see legend) so as to describe the relationship between the boxed components. The hierarchical levels are as follows: I - Scientific and Technological Base/International Agreements, II - Recognized National Standards Organizations, III National Standards or Instrument Standards, IV - Artifacts used for transfer or control, $V$ - Instruments for Transfer, and VI - point of application of standards. NBS participates actively at all six of these levels. Briefly, NBS (box (1) in fig. 2) calibrates precision reference specimens (5) using a stylus instrument/computer calibration system (4). Instruments (7) are then used to transfer these calibrations to further specimens with which the user (8) calibrates his instruments. The measurement loop is closed when a user sends a precision reference specimen directly to NBS for calibration. In discussing figure 2 the relationship of the components will be more easily understood if the levels are not described 


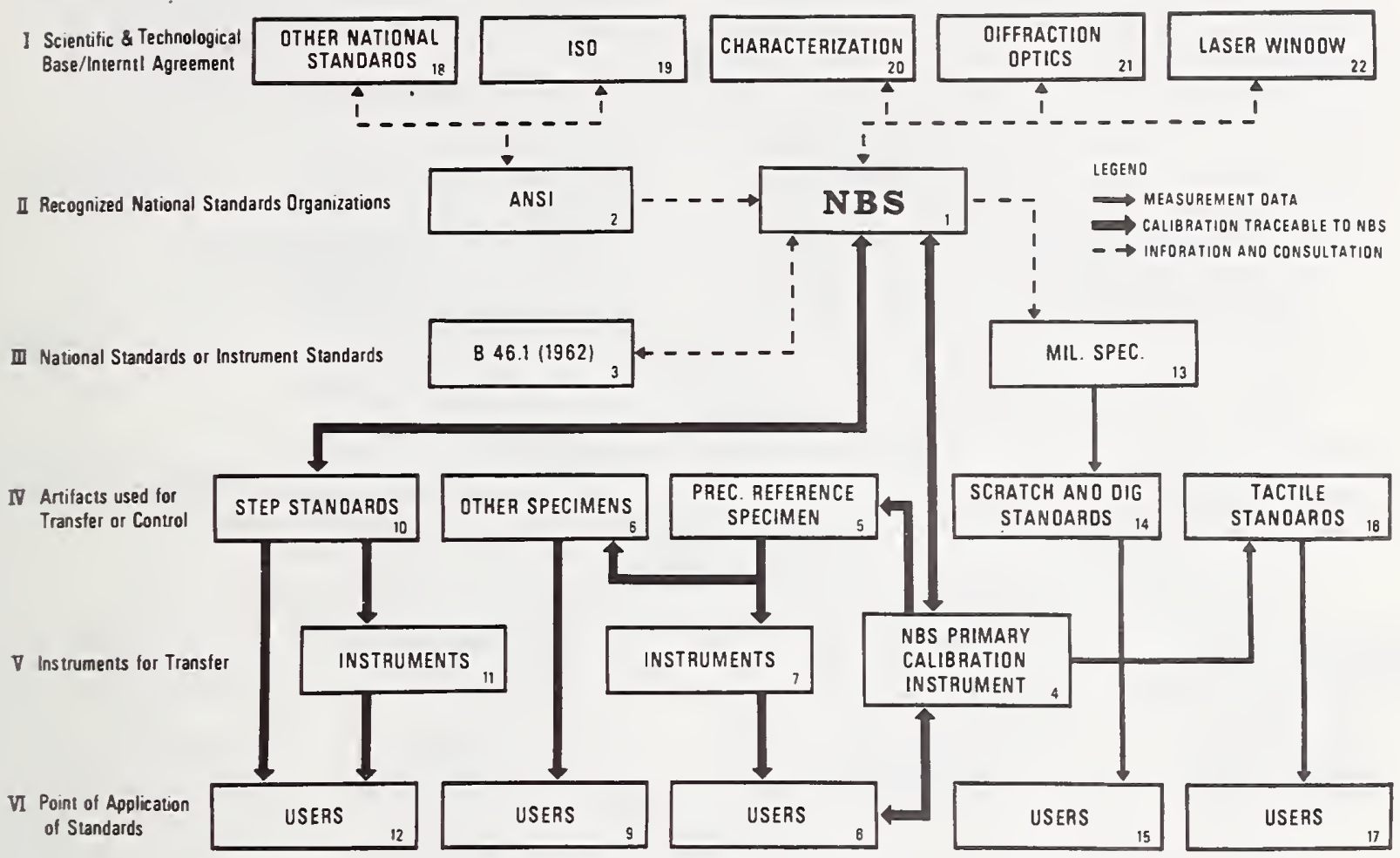

Figure 2: Surface finish measurement system infrastructure

in numerical order.

The structure of figure 2 is employed uniformly for all National Measurement System studies in the Mechanics Division. Another representation of the system, a calibration flow chart is given in figure 3 . Starting from the top, standards organizations produce documentary standards which NBS interprets through the inputs of science and technology. The resultant primary calibrations are disseminated through a variety of metrology laboratories to industrial users.

\subsubsection{Documentary Specification Institutions}

\subsubsection{Standardization Institutions}

In figure 2, level 1 includes other National and International Standards Organizations e.g. International Organization for Standardization (ISO). The corresponding ISO Technical Committee (19) TC-57 is chaired by the USSR and has, until recently, been ignored by many western countries, including the U.S., for political reasons. The American National Standards Institute (2) recently appointed a delegate to ISO/TC-57 and is in the process of accepting the chairmanship of two TC -57 subcommittees. Since travel to the USSR must be provided by the delegate or his company it is often very difficult to maintain continuity in the U.S. participation in this ISO work. At this writing an experienced specialist in surface work is presently providing his own financial support to participate as a delegate to ISO-57.

While there are 266 ISO standards published per year, the surface standards have not as yet reached the maturity required for adoption. Table 1 lists the TC -57 subcommittees. NBS has been unable to participate in ISO/TC-57 due to travel restrictions.

Level I, figure 2 includes input from other national standards organizations. The U.S. ANSI Committee for Surface Texture (B46) has achieved good uniformity with Canadian. British and proposed ISO standards. On the other hand there is considerable conflict with French, German and other European national standards groups.

A particularly influential international group, the International Institution for Production Engineering Research (CIRP) conducts yearly international conferences throughout the world, a portion of which are devoted to surface finish work. The NBS representative was elected to full membership in 1975.

There are no legal or regulatory standardization institutions for surface finish in the U.S. The military specification is man- 


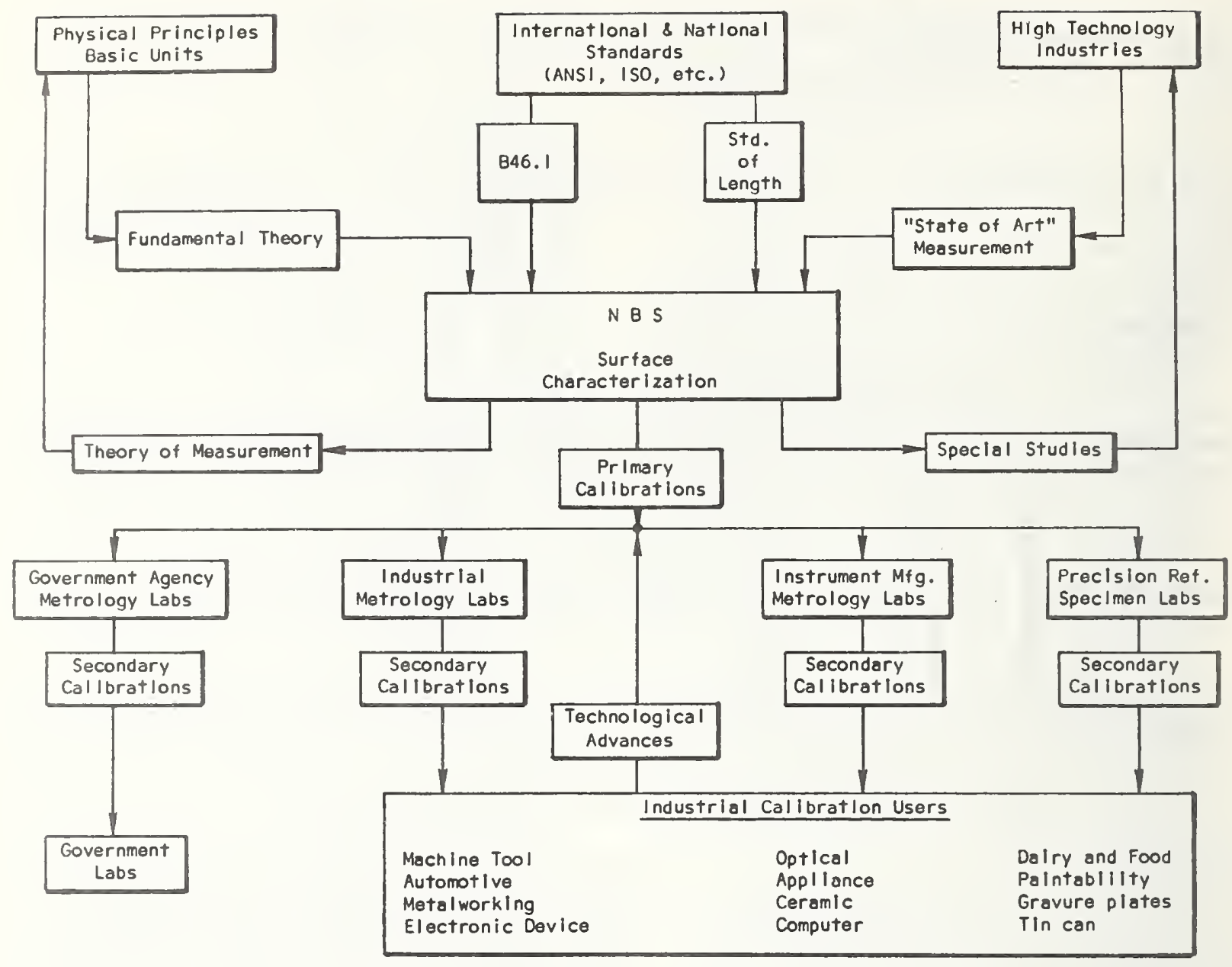

Figure 3: Surface finish calibration flow chart

Table 1: Subcommittee Chairmanships for ISO/TC-57

Metrology and Properties of Surfaces (Standardization of the Microgeometry of Machined Surfaces)

TC-57 Metrology and Properties

of Surfaces ....... USSR

$\mathrm{SC1}$ Instruments and devices for the measurement of surface

roughness ........ USSR

SC2 Roughness Comparison specimens and devices for the calibration of instruments ...... UK

SC3 Instruments and devices for the measurement of waviness, roundness and straightness. UK

SC4 Geometrical Parameters of the Surface ....... USSR

SC5 Typology of Surfaces . . . France

SC6 Relation of surface

irregularities to

functional properties.... *
$\mathrm{SC7}$ Physical parameters of surfaces and surface layers . *

*USA is presently negotiating for these committee chairmanships.

atory only for military hardware procurement. Level II of figure 2 includes the American National Standards Committee which appoints an industrially based committee (B46) to develop and periodically revise a voluntary engineering standard. NBS has one representative on B46 and one of the subcommittee concerned with measurement and instrumentation. NBS interprets and carries out the provisions of the standard and is playing a major role in the present revision of the 1962 documentary standard for surface texture, B46.1. The military specification (MIL-ABC-STD-50) is derived directly from the B46.1 standard and will not be discussed further. 
Table 2: List of recommended ISO surface standards (published and under review - 1974)

\section{ISO Recommended Standards}

ISO/R468-1966

ISO/R1878-1970

- Surface Roughness

- Classification of Instruments and Devices for Measurement and Evaluation of the geometrical parameters of surface finish

IS0/R1879-1970

- Instruments for the measurement of surface roughness by the profile method - General statements Terms and Definitions

ISO/R1880-1970 - Instrument for the measurement of surface roughness by the profile method - Contact (stylus) instruments of progressive profile transformation - Profile recording instruments

\subsubsection{Survey of Documentary Standards}

Four "Recommended" ISO standards (see table 2) have been distributed among ISO members for possible revision and are expected to be approved within the next few years.

The American National Standard B46.1 was adopted in 1962 and is presently under revision. Some idea of the material covered in the standard can be obtained from table of contents:

1. General

2. Classification of Terms and Ratings

Related to Surfaces

3. Designation of Surface Characteristics

4. Stylus Type Instruments

5. Precision Reference Specimens

6. Roughness Comparison Specimens

7. Appendices

The full table of contents is given in appendix B.1. After defining the terms used in the standard a preferred series of roughness standards is prescribed and the symbols used to designate surface characteristics on drawings are detailed. The present standard only recognizes the stylus type of instrument, which is similar to a high fidelity phonograph pick up. When the transducer is drawn across the specimen surface, the fine stylus follows the microdetails of the surface profile and records a magnified profile of the surface. At the same time a built-in analog computer generates the AA roughness value which is displayed on a panel meter. The standard specifies the electrical and mechanical properties of such instruments including detailed discussions of the stylus shape and force, and the methods for obtaining a reference surface (datum) relative to which the profile is measured. The precision reference specimen defined by the standard will be discussed with Level IV along with tactile standards.

The standard recognizes only Arithmetic Average roughness as a quantitative measure of surface texture. It has been clearly demonstrated in a number of papers that $A A$ alone does not characterize the surface well enough so that the surface texture can be related to function. An unanticipated conclusion of this National Measurement System study was the widespread and generally unrecognized need among users for a variety of surface finish characterizing parameters. A recent internal NBS report (appendix B.2) gave a particularly clear discussion of limitations of the most used parameters ( $A A$, RMS roughness, peak height and bearing area) and urged the adoption of other parameters which are sensitive to the periodicity of roughness along the surface. This restriction to $A A$ is probably the most severe limitation of the present standard and it is to be hoped that this deficiency will be corrected during the current revision.

A second limitation of the standard is the exclusion of a 11 roughness measuring techniques other than stylus instruments. Thus, the standard fails to recognize the increasing use of multiple beam interferometry and light scattering for measuring surface roughness. The latter technique is particularly attractive as non-contacting, on-line measurement method. The current state of the art in optical measurement of roughness is reviewed in a recent NBS internal report (appendix B.6). NBS is frequently called upon to carry out special measurement studies at the forefront of measurement technology. These experiences are studied and form the basis for special investigations which result in recommendations to a committee of the American Nationa 1 Standards Institute.

It is not practical to list every voluntary engineering standard which incorporates some surface finish requirement. Some examples are:

Surface Comparison Standard (1958) (Cast Surfaces)

Surface Finish (RMS) (1960) NSA823

Surface Finish as Cast for Die Casting (1964)

Surface Finishes (1948) machined

Surface Requirements for

Metallic Surgical Implants 1968

Surface Roughness Designation
SAE 107CAS

ADKE 18

AIR3

ASTF86

NSA30 
Surface Texture Control (1968)

SAEJ449A

Surface Texture Measurement of

Cold Rolled Sheet Steel (1969)

Surface Texture, Roughness,

Waviness and Lay (1964)

Surfaces for Dairy Equipment Sanitary Standards

SAEJ911

SAE291DAS

DFI2000

\subsubsection{Instrumentation System}

\subsubsection{Measurement Tools and Techniques}

Industrial measurements of surface finish employ a wide variety of instrumentation. While stylus instruments predominate, multiple beam interference microscopes, light scattering devices and glossmeters, pneumatic instruments, and tactile and visual comparators are also widely used. Since the B46.1 standard specifies the characteristics of stylus instruments (7, fig. 2) only, they are used exclusively in the calibration chain to the user $(8,9,12)$. For example, the stylus tip radius, stylus shape, shank angle, stylus force, stylus support and tracer head supports are carefully specified. of particular importance is the traversing length of the stylus as it moves across the surface and the relationship of this to the roughness width cutoff (the greatest spacing of repetitive surface irregularities to be included in the measurement of average roughness height). In addition, the electrical properties of these instruments are carefully specified so as to insure that the same surface characteristics will be measured by all complying instruments.

Stylus instrumentation has reached a high degree of sophistication, close to the fundamental 1 imitations imposed by nature, i.e. single atom steps. A typical instrument is shown in Figure 4 . Stylus size cannot be reduced appreciably (to improve horizontal resolution) since the stylus pressure now approaches the yield strength of most materials. Vertical resolutions in the tenth microinch range $(2.5 \mathrm{~nm})$ can be achieved, although this distance corresponds to the depth of the stylus damage in al1 but the hardest metals. The advent of the mini-computer has enabled the coupling of a dedicated computer and a stylus instrument so that much improved calibrating accuracy has been achieved. The NBS system was developed and calibrations were formalized in July 1973. The instrument wi 11 be described in section 4.1. The measurement rests on a combination of the defined unit of length and the definition of $A A$ roughness in $B 46.1$ (see section 2.1).

Calibration of surface roughness instrumentation is achieved through the use of Precision Reference Specimens (5) consisting of ruled surfaces on hard materials, typ- ically glass and electrodeposited nickel. B46.1 defines the Precision Reference Specimen as follows: "Surface Contour - The normal surface profile of Precision Reference Specimens of roughness height shall consist of a series of isosceles triangles having included angles of $150^{\circ}$. A flat region is permitted at the bottom of the grooves, provided that both the roughness height rating and the spacing of the grooves meet the following tolerance for accuracy .... Accuracy - Roughness values of Precision Reference Specimens shall not vary from the designated value by 1 microinch or 3 percent, whichever, is the larger. The average spacing of the grooves shal1 be within 2 percent or 20 microinches (whichever is the smaller) of the theoretical spacing corresponding to the nominal roughness height. Uniformity - The average deviation of roughness height of individual grooves of any Precision Reference Specimen shall not exceed 4 percent of the total roughness height. The average deviation of the groove spacings on a given Precision Reference Specimen shall not exceed 3 percent of the average spacing."

Precision Reference Specimens with roughness heights (AA) 20 microinches or smaller can be used to estimate the radius and determine the condition of the stylus in an instrument since a worn or damaged stylus will fail to "bottom" in the close spaced grooves.

A recent NBS study of the most frequently used Precision Reference Specimen, the Cali-Block, showed that that distribution of $A A$ values over the 120 microinch and the 20 microinch patches can be characterized in terms of their standard deviation $(\sigma)$ from the mean roughness value (see appendix B. 3 ). These $\sigma$ values can then be combined with other uncertainties to describe the uncertainty of the whole measurement process. The $3 \sigma$ value for the deviation from the mean AA value was about 2 microinches for both the 120 and 20 microinch patches. This study resulted in recommendations on sampling the Cali-Block surface when calibrating instruments.

Until July 1973, a special Cali-Block artifact standard was maintained by NBS and all calibrations were comparisons between the block to be calibrated and the artifact standard. Since July 1973, the computer based calibration procedure has been used (see section 4.1).

Other specimens (6) which do not conform to B46.1 can now be calibrated with the new computer system. Some typical precision reference specimens are shown in figure 5 . As a result of revision of $B 46.1$ it is anticipated that other precision reference specimens, particularly some good foreign 


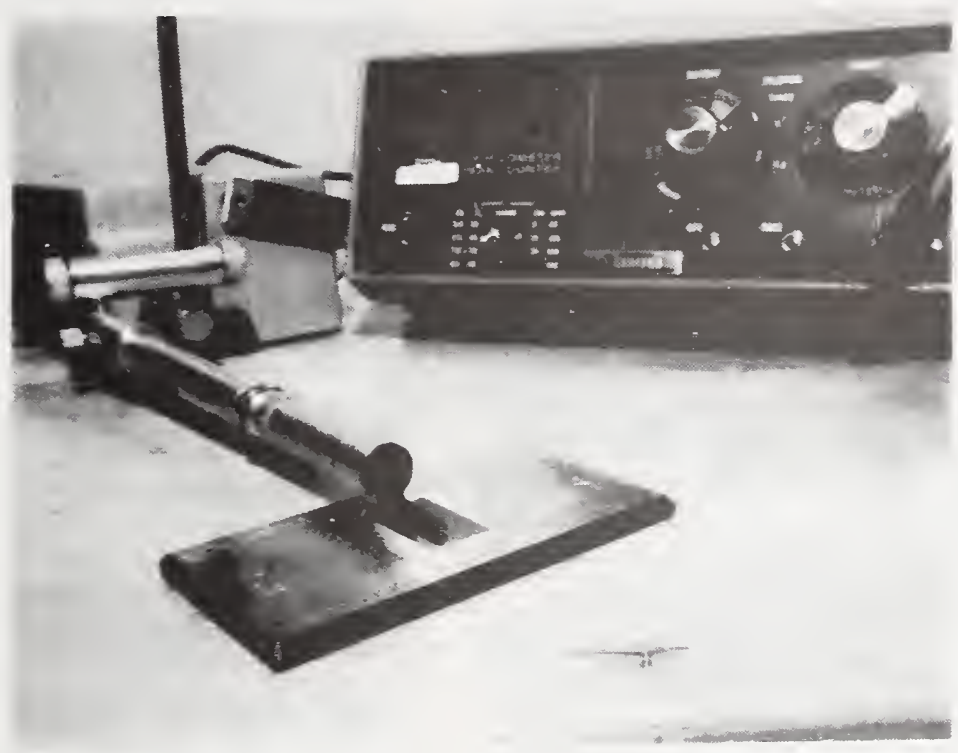

Figure 4: Typical stylus instrument

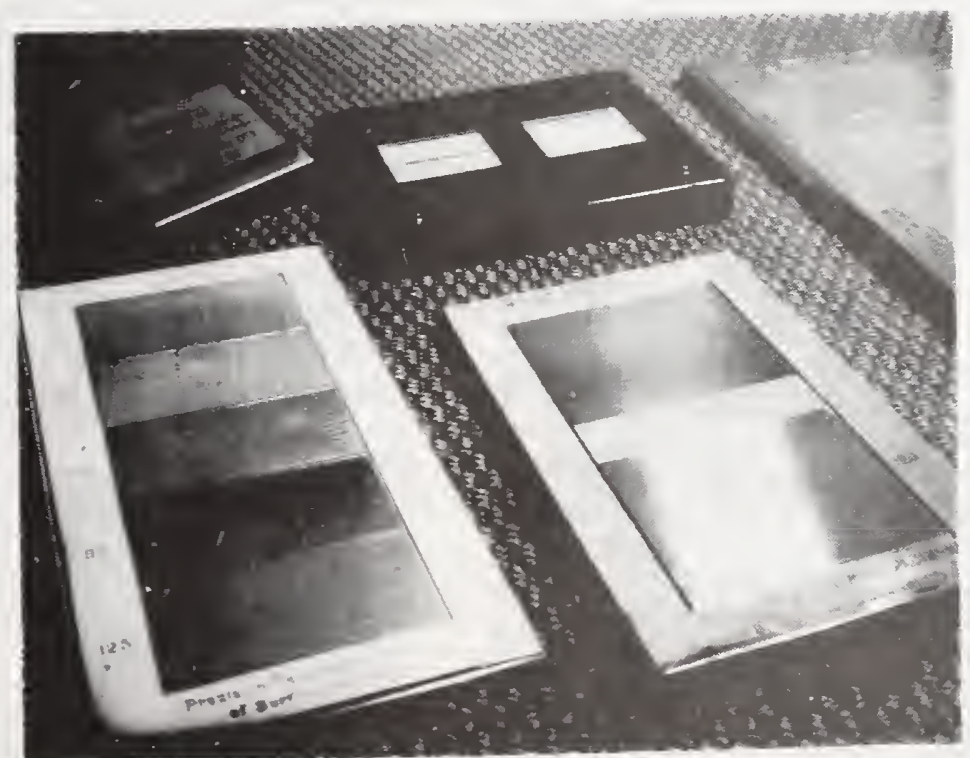

Figure 5: Precision reference specimens of roughness 
specimens, will be included in the rewritten standard. NBS has tentatively studied the possibility of developing a device which is capable of calibrating and testing a stylus instrument over a wide range of roughness values and with a variety of surface waveforms. The instrument which was evaluated consisted of a piezoelectric expander with a built in interferometer, illuminated with a well known wavelength. The interferometer serves as a built in calibrator and can be coupled to a servo system so that deflection can be precisely controlled. While the study revealed that the instrument would be costly and require a considerable investment of labor, it is clear that it would have wide application in micrometrology. Design and construction of this instrument have been deferred until resources become available.

A special case of surface roughness measurement is thin film step calibration. The calibration chain for step standards relies on well established interferometric procedures and is not based on a national standard. Step heights are measured by comparison with an interferometrically measured step of similar size using stylus instruments (7). The new computer roughness measuring system also provides for careful curve fitting of step profiles so as to improve the accuracy of step height measurements. Steps are also calibrated using two beam and multiple beam interferometers (11). Again in the case of steps, there is an increasing need for improved sensitivity and accuracy which will be met by the new NBS system.

The principle users (12) are the microcircuit and thin film industries, as well as the developing ion beam machining industry who employ specially manufactured thin film step standards calibrated by NBS.

Tactile Standards (16) are employed by machinists for visual and tactile comparison with machined surfaces in order to determine the approximate roughness of the surface. In the surface roughness standard, B46.1, page 14-15, these Roughness Comparison Specimens are described and tabulated according to the roughness values, lay, and tolerances for uniformity. These specimens are calibrated with stylus instruments according to the roughness width cutoffs given in B46.1. They are widely used in machine shops of all types.

Al1 surface roughness calibrations follow the path indicated in figures 2 and 3 . NBS calibrated specimens serve as secondary standards for other calibration laboratories which in turn provide calibrations for instruments used by hundreds of types of industries, Department of Defense and other government agencies. There is no enforcement network. The integrity of the system depends on occasional NBS calibrations directly for the user and round robin intercomparisons.

Scratch and Dig Standards (14) are based on Military Specification MIL-0-13830A (11 Sept. 1963). The Scratch and Dig specifications are now being revised by an American Society for Testing Materials Committee so they can serve as a more useful standards. The principle application of this standard is in characterizing the surface of high quality and diffraction limited optics (21).

\subsubsection{The Instrumentation Industry}

Surface roughness measurements, in accordance with $\mathrm{E} 46.1$, employ stylus instrumentation as described in the section above. Among the western countries the U.S., Great Britain and Germany are the leading suppliers of the 25,000 stylus instruments and the Precision Reference Specimens now in use in the U.S. A highly flexible calibration quality instrument costs well over $\$ 20,000$, while shop quality instruments cost less than $\$ 1,000$. Table 3 lists U.S. and foreign manufacturers ( $\mathrm{mfg}$. names deleted) of stylus instruments, precision reference specimens, light scattering instruments such as glossmeters and interference microscopes. Sixty five percent of stylus instruments are ten years old and almost a third are twenty years old, explaining why the U.S. stylus instrument yearly sales in 1972 did not exceed $\$ 2$ million. As will be shown in section 3.1 .2 , after a $\$ 39$ million instrument investment, industry spends approximately $\$ 50$ million in labor for surface measurements affecting $\$ 42$ billion of proTable 3: U. S. and foreign manufacturers of instrumentation
for measuring surface roughness $\begin{array}{llll}\text { INSTRUMENT } & \text { Stylus } & \text { Prec. Ref. Glossmeters and Interference } \\ \text { MANUFACTURERS } & \text { Instruments } & \begin{array}{l}\text { Specimens } \\ \text { Light Scattering Microscope }\end{array}\end{array}$

U.S.A.
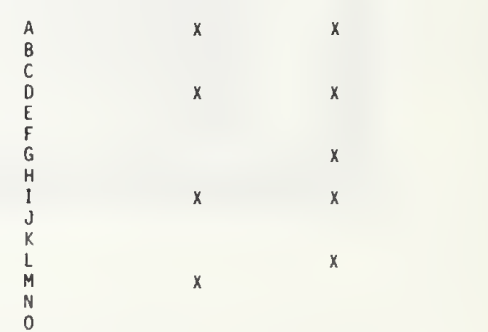

Foreign (disU.S.A.)

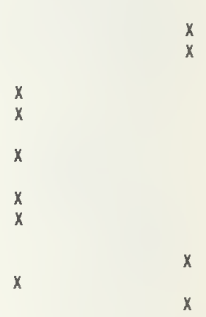

$x$

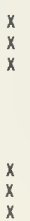


ducts each year. Finished surfaces and roughness measurements are used throughout most manufacturing industries. The distribution of stylus instruments among metalworking industries is given in table 8 .

Interference microscopes are used to measure thin film steps and surface roughness values less than a quarter of a micrometer $(\lambda / 2)$. They are particularly useful where the surface is metallic and a non-contacting measurement must be made. It is possible to use a soft metal to obtain an impression or replica of a portion of a surface which is inaccessible to stylus instruments and to examine the replica with an interference microscope.

\subsubsection{Reference Data}

There is a pressing need for both measurements and theories relating surface finish to part function. Industries possessing such data consider it proprietary, so it remains unpublished and often even its existance is unknown. Two exceptions are tables 4 and 5 listing surface finish requirements for automobile motor and automatic transmission components. The source of this information is proprietary. Industry as a whole suffers from this unwarranted secrecy, since small manufacturers do not have sufficient $R$ and $D$ capability to investigate problem areas, and large companies cannot benefit from each others' $R$ and $D$ as is possible in much of science and engineering.

\subsubsection{Reference Materials}

The only "reference materials" used in surface finish are the precision reference specimens of hard plated nickel and glass, and hard thin film deposits used in step calibrations. These have been discussed in 2.2.2.1.

\subsubsection{Science and People}

New measurement technology grows out of demands generated by refinement of existing technology and the birth of new technology. The measurement system is alerted by demands upon NBS and instrument manufacturers for improved measurements, and by articles in the scientific and technical literature exposing measurement deficiencies. As a result, new problems are analyzed (fig. 2, boxes 20, 21, and 22) and new instruments proposed or developed. These serve as input to the measurement system, which, if the system is responsive, results in continued improvement of the system. In surface characterization the new technologies which demand improved measurements include laser mirror finish for laser fusion experiments, magnetic tape heads for video and computer applications, high quality optical surfaces, semiconductor surfaces for integrated circuit devices with ever increasing device density, thin film devices, surgical implants such as hip joints, optical fiber surfaces for low loss communication systems and gauge blocks for length calibration.

A study of the literature collection in surface finish maintained by NBS reveals that most technical papers in the field come from European countries, Russia and Japan. U.S. University studies are limited to a very few mechanical or production engineering departments, and their interest is usually peripheral. Research in the relationship between surface finish and such parameters as friction, wear, paintability, corrosion, light scattering, heat exchanging, radiative properties, gauge block wringing and a host of others, is very badly needed. NBS has made a considerable effort to attract research associates from industry and universities to carry out such studies at NBS, but to no avail.

Surface characterization draws heavily from statistical analysis and communication theory in order to develop methods for dealing with the vast amount of information contained in a single surface profile. Such statistical parameters as the autocorrelation function, amplitude density function, mean slope, and average wavelength can be routinely calculated at NBS and by some instruments made in England and Germany. Hope for progress in relating finish to the function of the surface (i.e. bearing, appearance, etc.) presently lies in the application of these statistical parameters to function models.

Professional societies such as the American Society of Mechanical Engineers (ASME), Society of Manufacturing Engineers (SME), International Institution for Production Engineering Research (CIRP), and American Society of Testing Materials (ASTM), participate in standard writing activities, publish research in surface characterization, and organize national and international meetings. Unfortunately, an unusually large fraction of the knowledge involving the relationship between surface finish and function is considered proprietary and thus has no impact on the surface community. Instrument manufacturers conduct one day courses and other special programs on surface measurement techniques. Qualifications of people in this field range from machinist to $\mathrm{Ph} . \mathrm{D}$. in mechanical engineering. 
Table 4: Surface roughness of automobile motor production parts in microinches AA

\begin{tabular}{|c|c|c|c|c|}
\hline \multirow[b]{2}{*}{ Component } & \multicolumn{2}{|c|}{ Car No. 1} & \multicolumn{2}{|c|}{ Car No. 2} \\
\hline & $\begin{array}{l}\text { Acceptance } \\
\text { Roughness }\end{array}$ & Mfg. Process & $\begin{array}{l}\text { Acceptab } \overline{1 e} \\
\text { Roughness }\end{array}$ & Mfg. Process \\
\hline $\begin{array}{l}\text { Cylinder Block: } \\
\text { Cylinder Bore } \\
\text { Tappet Bore } \\
\text { Main Bearing Bore } \\
\text { Head Surface }\end{array}$ & $\begin{array}{l}16-20 \\
60-75 \\
60-80 \\
40-50\end{array}$ & $\begin{array}{l}\text { Hone } \\
\text { Ream } \\
\text { Bore } \\
\text { Mi11 }\end{array}$ & $\begin{array}{l}20-25 \\
80-120 \\
130-150 \\
190-210\end{array}$ & $\begin{array}{l}\text { Hone } \\
\text { Ream } \\
\text { Bore } \\
\text { Mi 11 }\end{array}$ \\
\hline $\begin{array}{l}\text { Piston: Skirt } \\
\text { Pin Bore } \\
\text { Piston Pin }\end{array}$ & $\begin{array}{r}45-55 \\
30-38 \\
9-12\end{array}$ & $\begin{array}{l}\text { Grind-Polish } \\
\text { Grind-Lap }\end{array}$ & $\begin{array}{c}40-50 \\
11-13 \\
3-5\end{array}$ & $\begin{array}{l}\text { Grind } \\
\text { Grind-Lap }\end{array}$ \\
\hline $\begin{array}{l}\text { Crankshaft: } \\
\text { Main Bearing Journal } \\
\text { Connecting Rod Journal }\end{array}$ & $\begin{array}{l}4-6 \\
4-6\end{array}$ & $\begin{array}{l}\text { Grind-Polish } \\
\text { Grind-Polish }\end{array}$ & $\begin{array}{l}6-9 \\
6-9\end{array}$ & $\begin{array}{l}\text { Grind-Polish } \\
\text { Grind-Polish }\end{array}$ \\
\hline $\begin{array}{l}\text { Camshaft: Journal } \\
\text { Cam }\end{array}$ & $\begin{array}{l}4-6 \\
15-20\end{array}$ & $\begin{array}{l}\text { Grind-Polish } \\
\text { Grind-Polish }\end{array}$ & $\begin{array}{l}14-18 \\
22-26\end{array}$ & $\begin{array}{l}\text { Grind-Polish } \\
\text { Grind }\end{array}$ \\
\hline $\begin{array}{l}\text { Rocker Arm: Shaft } \\
\text { Bore }\end{array}$ & $\begin{array}{l}14-20 \\
29-32\end{array}$ & $\begin{array}{l}\text { Grind } \\
\text { Hone-Polish }\end{array}$ & $\begin{array}{l}20-22 \\
30-40\end{array}$ & $\begin{array}{c}\text { Grind } \\
\text { Hone-Polish }\end{array}$ \\
\hline $\begin{array}{l}\text { Valves: } \\
\text { Intake Valve Stem } \\
\text { Intake Valve Seat } \\
\text { Exhaust Valve Stem } \\
\text { Exhaust Valve Seat }\end{array}$ & $\begin{array}{l}34-38 \\
25-40 \\
18-20 \\
34-45\end{array}$ & $\begin{array}{l}\text { Grind } \\
\text { Grind } \\
\text { Grind } \\
\text { Grind }\end{array}$ & $\begin{array}{l}16-22 \\
30-40 \\
14-20 \\
30-35\end{array}$ & $\begin{array}{l}\text { Grind } \\
\text { Grind } \\
\text { Grind } \\
\text { Grind }\end{array}$ \\
\hline $\begin{array}{l}\text { Tappet: Face } \\
\text { O.D. }\end{array}$ & $\begin{array}{c}4-5 \\
14-18\end{array}$ & $\begin{array}{l}\text { Grind } \\
\text { Grind }\end{array}$ & & \\
\hline $\begin{array}{l}\text { Hydraulic Lifter: Face } \\
\text { O.D. }\end{array}$ & $\begin{array}{l}22-25 \\
14-16\end{array}$ & $\begin{array}{l}\text { Grind-Polish } \\
\text { Grind-Polish }\end{array}$ & $\begin{array}{l}15-20 \\
13-14\end{array}$ & $\begin{array}{l}\text { Grind } \\
\text { Grind }\end{array}$ \\
\hline
\end{tabular}

Table 5: Surface roughness of automobile drive-chain components in microinches AA.

Automatic Transmission Parts

Front Pump Shaft Journal

Front Pump Shaft Thrust Surface

Reverse Gear Drum - Braking Surface

Intermediate Shaft Journal \#1

Intermediate Shaft Journal \#2

Center Main Shaft Journal

Center Main Shaft Thrust Surface

Output Shaft Journal \#1

Output Shaft Journal \#2

Output Shaft Journal \#3

Front Drum - Braking Surface

Clutch Plate

Main Shaft Journal \#1

Main Shaft Journal \#2

Low Range Reaction Member - Thrust Surface \#1

Low Range Reaction Member - Thrust Surface \#2

Front Drum - Braking Surface

Brake Drum - Front Rear

Clutch Pressure Plate

King Pin

Universal Spider Race

\begin{tabular}{c} 
Acceptable \\
Roughness \\
\hline $18-22$ \\
$11-14$ \\
$150-170$ \\
$6-7$ \\
$50-60$ \\
$23-27$ \\
$20-30$ \\
$14-16$ \\
$10-15$ \\
$27-32$ \\
$90-110$ \\
$16-24$ \\
$20-25$ \\
$25-30$ \\
$35-40$ \\
$65-75$ \\
$90-110$ \\
$65-75$ \\
$75-85$ \\
$40-50$ \\
$6-8$ \\
$14-16$
\end{tabular}




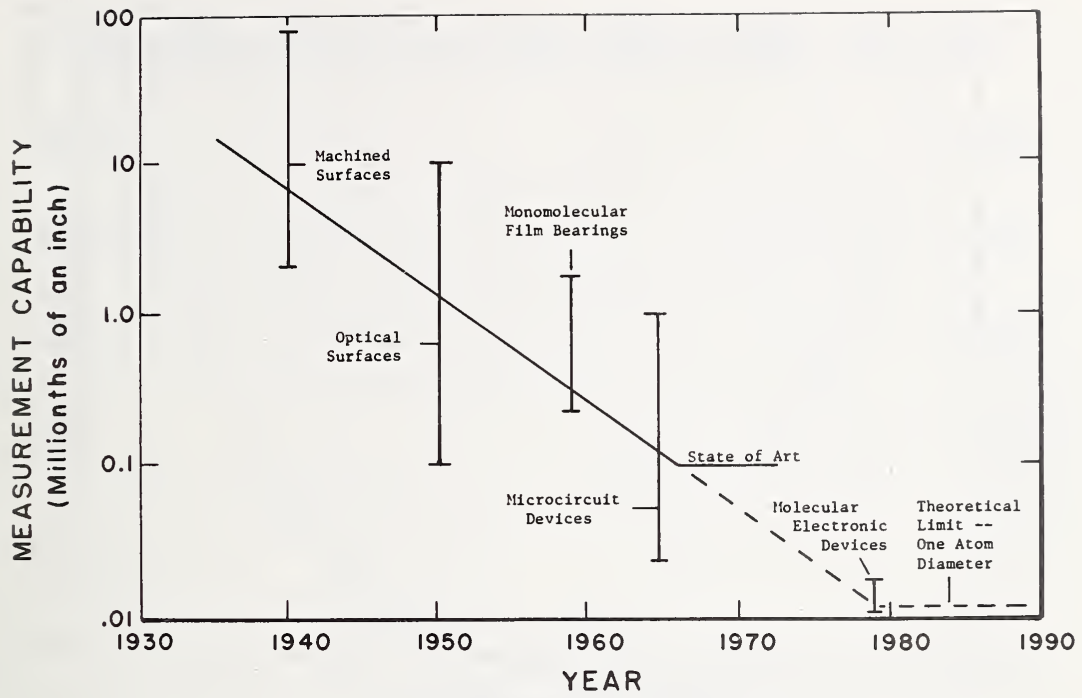

Figure 6: Surface finish measurement capability vs time (1930 - 1980)

\subsection{Realized Measurement Capabilities}

Figure 6, a logarithmic plot of surface finish measurement capability from 1930 to 1980 (projected), puts the measurement system in historical perspective. Some key features included the two decade improvement in accuracy between the 1930's and the 60 's, the terminations of improvement at the 0.1 microinch $(0.025 \mu \mathrm{m})$ level in the mid 60 's and the urgently needed single atom step capability which is already being requested by the semiconductor industry and surface scientists. The thrust toward microminiaturization will necessitate the single atom step level of measurement in the very near future.

The accuracies of NBS calibrations in surface finish and thin film steps are dependent on the magnitude of the quantity measured and are shown in figures 7 and 8. Both measurements are limited by step calibration accuracy. A new polarizing interferometer under development at NBS will considerably improve the accuracy of both measurements. A sample calibration report is reproduced as appendix B.4.

The accuracy required by users varies from a few high technology industries measuring close to the NBS level (computer discs and drums, semiconductor devices, bearings, surgical implants, etc.) to the machine shop level where accuracies of $25 \%$ at the 100 microinch $(2.5 \mu \mathrm{m})$ level are the rule.

The accuracy of calibrations using precision reference specimens is not appreciably influenced by temperature or humidity. Major inaccuracies in the transfer have been shown by NBS (appendix B.3), to be due to variations in $A A$ roughness across the surface of the artifact itself and are sufficiently small so that only high technology users and calibration laboratories need concern themselves.

\subsection{Dissemination and Enforcement Network}

\subsubsection{Central Standards Authorities}

There is no hierarchical system of physical standards (artifacts) in the surface roughness measurement system. The documentary standard (B46.1) provides the full prescription for surface propagation of surface roughness calibrations. Historically, the importance of surface measurements to the military and other government agencies focussed central responsibility for primary calibrations on NBS. Industry has strongly supported this NBS role because they have chosen to rely on NBS, as an independent, impartial measurement source. Thus, through the years, NBS calibration instrumentation has become the de-facto "artifact" standard 


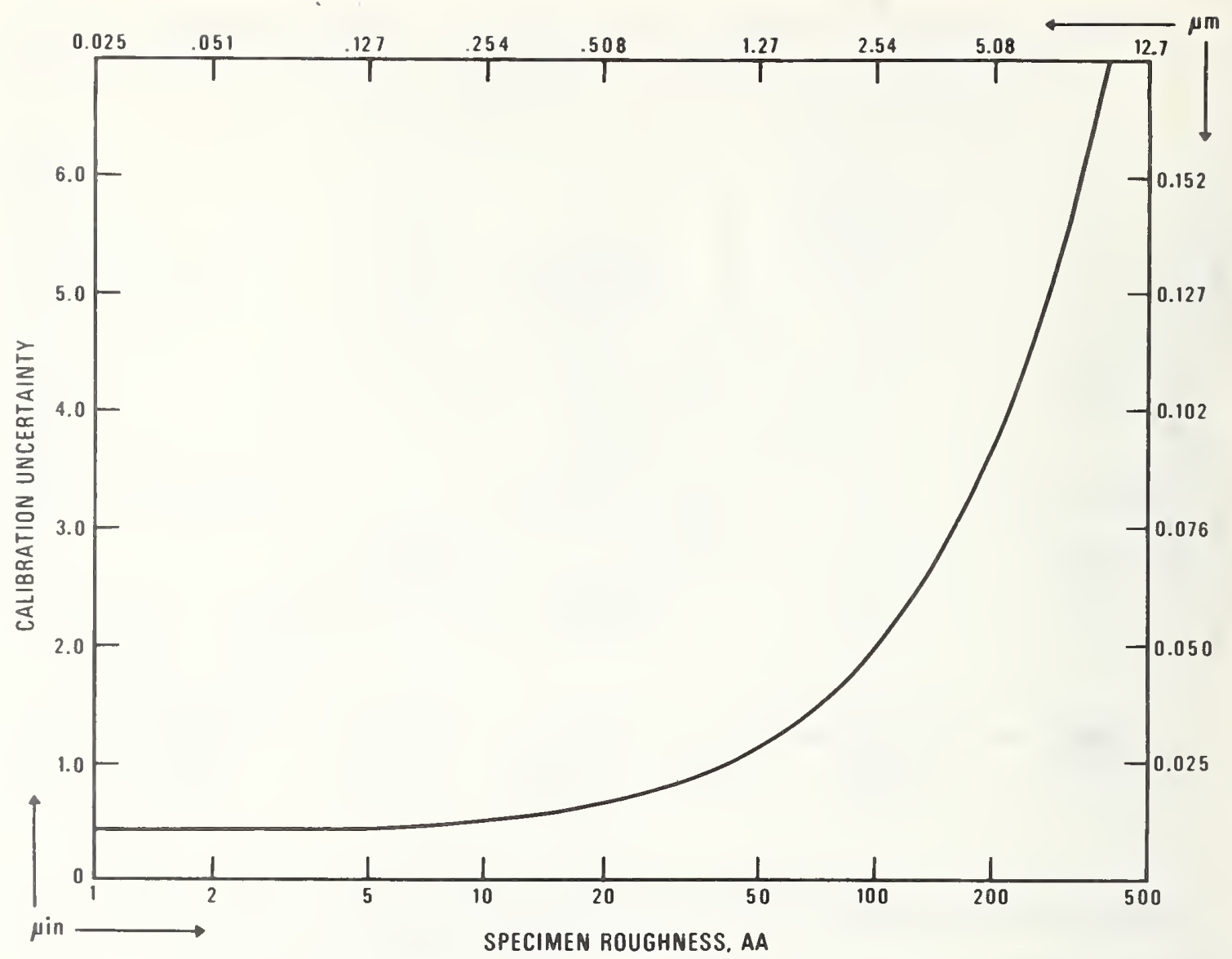

Figure 7: Calibration accuracy vs magnitude of surface roughness

in the USA through the primary calibration of precision reference specimens.

\subsubsection{State and Local Offices of Weights and Measures}

So far as NBS has been able to determine, state offices of weights and measures are not part of the surface finish or thin film step measurement chain.

\subsubsection{Standards and Testing Laboratories and Services}

Secondary transfer of surface roughness calibrations occurs in industrial and government laboratories and in instrument manufacturer laboratories (7). These organizations usually maintain one or two Precision Reference Specimens (5) which are recalibrated by NBS at one to ten year intervals. Stability of these artifacts is known to be very good. In the last five years precision reference specimens have been calibrated by NBS for 35 members of the prestigious National Conference of Standards Laboratories. Ten of these calibrations were performed in 1974 and projections for 1975 suggest an even greater number. As far as NBS can deter- mine, the majority of the 90 NCSL members who perform dimensional calibrations also perform surface roughness calibrations at some level. In addition, instrument and specimen manufacturers as well as a number of users employ NBS calibrated artifacts.

All of the above users calibrate specimens at the second, third, etc., level by comparing the NBS calibrated artifact with the one being measured. These are then distributed to secondary metrology labs and machine shops for day to day use in the calibration of production line instruments.

\subsubsection{Regulatory Agencies}

There are no governmental regulatory agencies for surface finish or this film steps although agencies like the Public Health Service exert indirect control in some instances (3.1.1.1). As discussed in 2.4.1, the integrity of these measurement systems is based on voluntary standards with the cooperation of NBS and professional societies. 


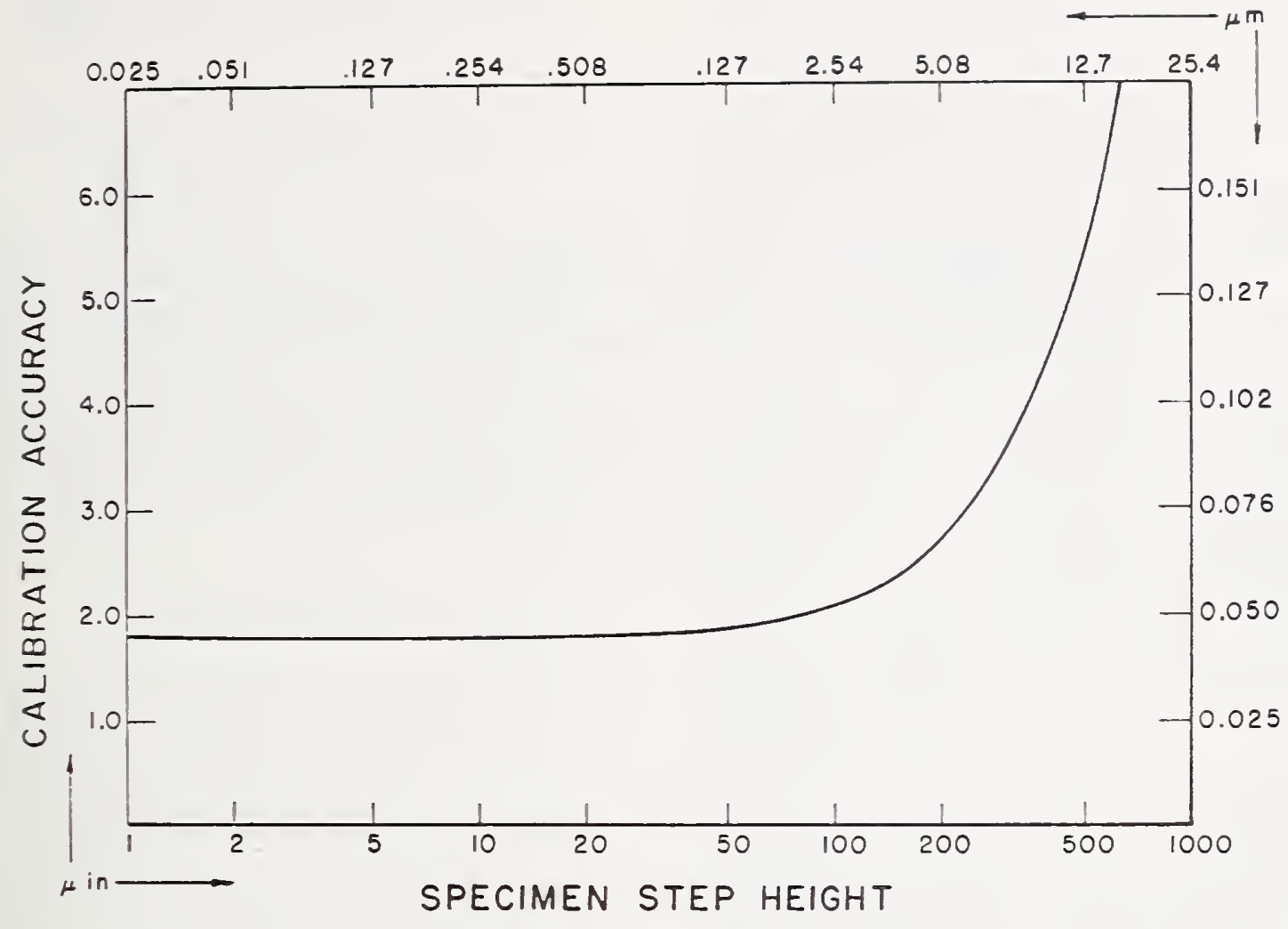

Figure 8: Calibration accuracy vs height of thin film roughness

2.5 Direct Measurement Transaction Matrix factors than business considerations.

The interaction among the various components of the surface finish measurement system can be succinctly described by means of the input-output transactions matrix of table 6 . Where applicable, Standard Industrial Classification (SIC) codes are given. In the left hand column each organization is listed as a supplier of information, goods or services and across the top of the matrix these same organizations are listed as users. The information within each box is coded according to the key shown.

All of the suppliers have been discussed above or will be described in section 4.3 . The measurement needs for a particular category, for example the automotive industry, vary so widely within the industry that some manufacturers measure with accuracies approaching that of NBS while others use only tactile comparison standards. Al 1 metalworking industries employ some measurements at the lowest level of accuracy in their machine shops and some manufacturing processes. Highlights regarding the major measurement system users are discussed in the next section, since the discussion has been developed more around technological 


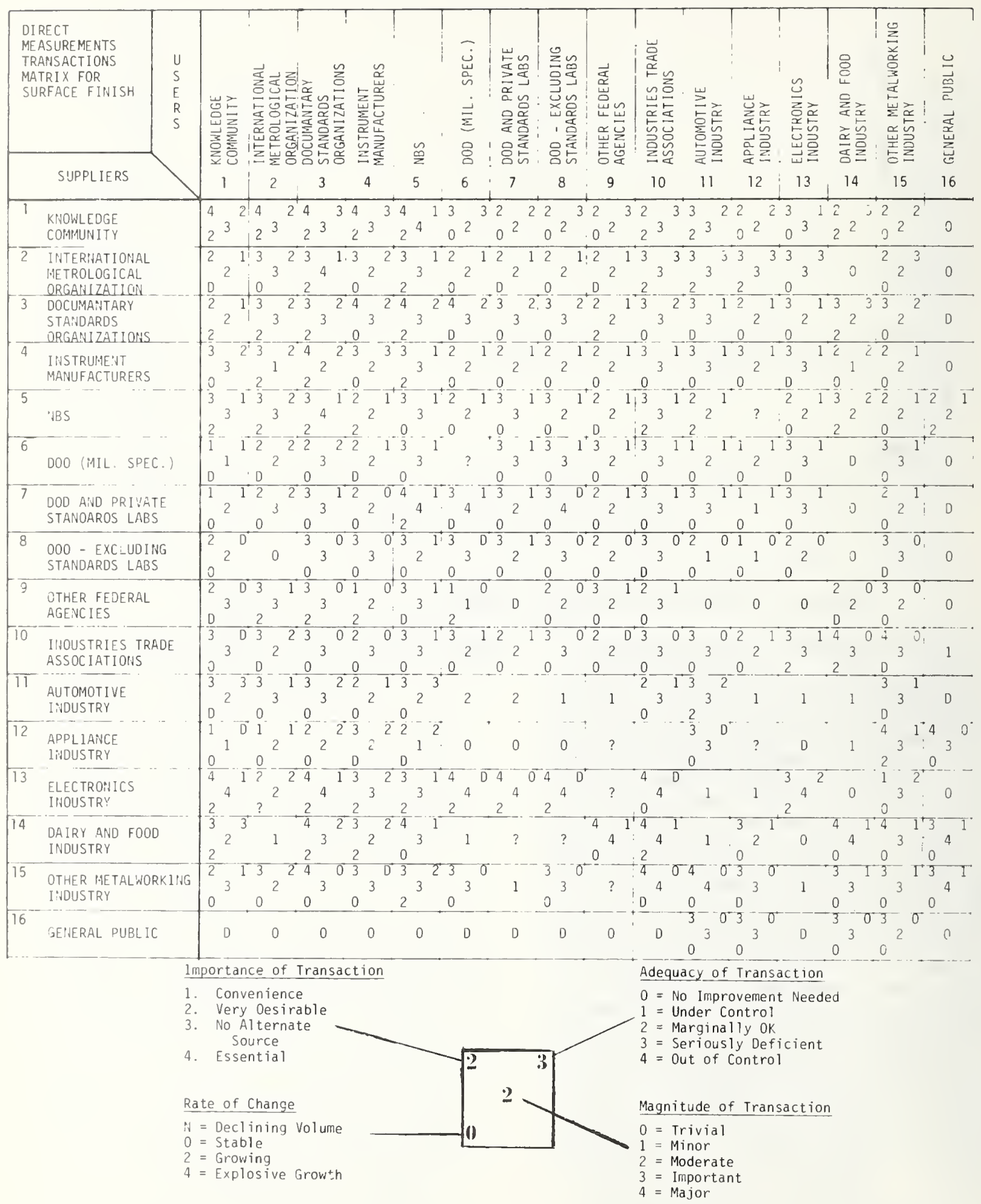


3. IMPACT, STATUS AND TRENDS OF MEASUREMENT SYSTEM

\subsection{Impact of Measurements}

\subsubsection{Functional, Technological and Scientific Applications}

Since all metalworking industries employ surface roughness measurements, ten typical areas will be discussed briefly in this section. They have been selected because of their broad interest or because of NBS involvement in their measurement problems. These ten micro-studies revealed a broad need for improved characterization in most areas, and a need for refined instrumentation in others.

\subsubsection{Dairy and Food Industry Storage and Distribution Containers}

The average household purchased $\$ 712$ worth of dairy products during 1974 and generated a 35 billion dollar dairy industry whose capital expenditures exceed $\$ 350$ million for 1974 alone.

(Statistical Abstract of the U.S., 1974). A large fraction of this capital expenditure is for milk handling, transporting and processing equipment. In the 1920's two trade associations and one professional organization formulated the first uniform standards for fittings used on milk pipe lines. Ultimately, the standards become popularly known as 3-A standards, for the three founding organizations. In 1944 the U. S. Public Health Service joined these three organizations in developing voluntary sanitary standards in the dairy industry. Today over 50 sanitary standards for the milk industry and a dozen for the egg and egg product industry have been adopted.

The role of surface finish in insuring sanitation through appropriate cleaning procedures has become a matter of some concern to the dairy industry (see appendix B.5, "The Public Health Significance of Surface Measurements"). Traditionally, the $3-A$ standards have relied on the requirement that the stainless steel surface have a Number 4 finish (8 microinches), equivalent to polishing with 150 grit silicon carbide (see Dairy Standard 3A "Accepted Practices for Permanently Installed Sanitary Product Pipelines and (leaning Systems"). This standard also includes the specifications for a Cast Surface Comparison Standard used to evaluate the surface finish of castings used in pipelines. These standards have served the dairy industry well over the past thirty years. At first it was believed that the highly finished stainless steel surface was necessary to prevent bacterial growth on surfaces and permit reliable sanitizing. However, studies on the cleanability of a variety stainless steel surfaces, some much less smooth than a Number 4 finish, revealed no significant difference in bacterial cleanability among a variety of finishes (see for example, 0. W. Kaufman et.al., Journal of Dairy Science 53 1, Jan. 1960).

However, there is considerable opposition, particularly from the Public Health Service, to relaxing the surface finish requirements. They point out that while the bacteriological swab-count of less than 100 per 8 in $^{2}$ of swabbed surface has officially been declared to be the acceptable safety level, and is achieved on rougher surfaces, the surface requirement serves another important function. In routine inspections, most dairy surfaces are subjected to the more practical visual inspection of a sanitarian. It is vital to detect the present of pits, cracks and inclusions, since these form tiny corrosion cells when they collect soil. These cells then generate corrosion pits which deepen at a remarkable rate. The grinding and polishing of these surfaces serves the purpose of removing cavities, pits and inclusions, while at the same time permitting easy visual inspection of surfaces. The pits, when present, serve as breeding grounds for bacteria as well as reservoirs for corrosive sanitizing solutions. Thus, in this case surface finish is a surface preparation and inspection requirement.

During October 1973, the Dairy and Food Industries Supply Association enlisted the aid of NBS in attacking the problem of proper characterization of product contact surfaces. There is considerable pressure from manufacturers to permit the use of new materials and surface finishes so that manufacturing, and thus product, costs can be reduced. Since the whole inspection system is involved, NBS is consulting with the Association in several areas in an attempt to delineate more clearly the range of acceptable surface finishes.

\subsubsection{The Surface Finish of Surgical Implants}

An unparallelled opportunity to serve one's fellow man by improving surface finish measurements exists in the area of surgical implants. The lifetime of these devices, for example an artifical hip joint, is not likely to exceed 10 years. R. C. Spragg, Director 
of Research for the Rank Taylor Hobson Company, discussed this problem in an article entitled, "The Interdisciplinary Nature of Surface Measurement" (Joint Measurement Conference, Boulder, Colorado, June 1972). Spragg discussed the evidence that boundary layer lubrication depends on both the velocity of the bearing and its surface finish. As the surface texture is improved, full hydrodynamic lubrication is obtained at lower and lower bearing velocities. Severe wear occurs when the critical velocity is not attained. The tendency to pit is related to the ratio of the total height of the surface roughness to the lubricant film thickness. It is obvious that hip joints seldom achieve high velocities and frequently achieve very low velocities.

Spragg points out that it is preferable to have one bearing surface, typically the socket, of low friction material. The ball is manufactured from a special alloy and is polished to a surface finish which is not measurable at present, but which is certainly well below the microinch level. A major problem is the detection of tiny ( 20 microinch) defects in the surface. Robert Averi11, Vice President of Meditec, Inc., a manufacturer of surgical implants, has urged NBS to accelerate the development of the Topografiner as a quantitative tool for measuring these very refined surfaces. American Society for Testing Materials Committee F-4 on Surgical Implants met on November 14-15, 1973, in Miami, Florida to discuss, among other things, the quantitative measurement of the surfaces of Implants. Robert Averill pointed out (in a private conversation) the total inadequacy of the present standard (F-86-69, "Surface Requirements of Metallic Surgical Implants"), much of it stemming from an incomplete knowledge of the relationship between surface finish and joint lifetime. Committee F-4 is presently studing this problem. NBS maintains a continuous dialogue with this industry in an attempt to assist in every possible way in this very difficult measurement problem.

\subsubsection{Gravure Illustrations}

The beautiful colored illustrations found in magazines, newspapers, packaging, catalogs, vinyl fabrics, and wall coverings are the result of the fully developed art of gravure printing. Gravure is a term for an intaglio process of printing illustrations from designs engraved or etched on copper, chromium and other metal plates and cylinders. Gravure is distinguished by its dense rich solids, by the unobtrusiveness of its screen, and by the delicate detail on loaded papers. The popularity of this medium is evident from the $\$ 2.8$ bizlion* of printed products produced in 1971. Cylinder gravure printing has enabled long runs of colored illustrations to be produced cheaply and rapidly. A detailed survey of Gravure printing for 1971, including market breakdowns, growth curves, and a prediction by the Department of Commerce that certain areas of printing will double in dollar value by 1980 .*

At the very heart of the Gravure process is the etched cylinder containing the information to be transferred through the printing process. In discussions with the author, an engineer in charge of producing the machines which manufacture, grind and polish the gravure cylinders, pointed out that much of the art of cylinder manufacture is proprietary. He was willing to state that the cylinders are machined to a 3 microinch finish with high technology diamond turning equipment. Copper cylinders are used with a 3 microinch finish in newspaper applications, but the beautiful magazine illustrations require a chrome plated cylinder where a polishing procedure generates a 1 to 1.5 microinch finish. Poor surface finish on these cylinders results in the "double exposure" appearance sometimes observed in colored illustrations.

While the industry is usually reluctant to discuss measurement processes which tend to expose their proprietary techniques, one design engineer did state that their 1-3 microinch surfaces were very difficult to measure and characterize, and a higher resolution surface finish instrument would make a important contribution to their technology, which is now measurement limited. Electron micrographs are used to obtain qualitative information, but cannot be used as a regular, quantitative inspection technique.

\subsubsection{Surface Finish Requirements for Automobile Motors, Transmissions and Brake Drums}

The huge number of surface measurements made per year by the automobile industry constitutes almost half of total number of such measurements made in the United States. Of these, the majority involve the drive chain. Table 4 , lists part of the total number of automobile motor surface finish requirements together with the associated manufacturing process for two automobiles made in the United States. Note that, while the higher priced car in the left column generaliy has more stringent surface requirements, this is

* Garvure Technical Association Bulletin Vol. XII, No. 2, 1972. 
not always the case. For example the piston pin and bore, intake and exhaust value stems, and hydraulic lifter have smoother surfaces specified for Car \#2, because of requirements generated by different motor designs.

Table 5 , lists the surface finish requirement associated with the automatic transmission, clutch, brake drums and other components of Car $\# 1$, together with the manufacturing process. Moving part failure is often related to the surface finish of the part, so that surface inspection is a major cost factor in automobile manufacture.

During 1971 about 8.5 million passenger cars were manufactured in the U.S. with tota 1 value of $\$ 40.6$ billion ( $3.9 \%$ of G.N.P.) (from Statistical Abstract of U.S. 1972). The number of surface finish measurements involved in maintaining the quality of these cars is staggering.

The surface finish requirements for diesel truck motors is considerably more stringent than for automobiles because of tighter dimensional tolerances. In a study of the performance and reliability of piston pins it was found some years ago that pins with 6-7 microinches roughness failed rapidly, while those with 5 microinches failed on run in. When finished with a final polish which is basically a fine circular grind to a finish of 4 microinches, performance was good and this pin is used in engine production. The nature of the finish rather than its roughness determined its performance. Today a 1 microinch finish is specified for these pins, even though this is really beyond the measurement capability of practical surface instrumentation. It is clear that the small reduction from 5 to 4 microinches is not responsible for the tremendously improved reliability. Since the manufacturer was unable to relate the character of the surface finish to the lubricating function and its failure, he merely tightened the surface requirement, thus increasing the cost. This is an example of the two major problem areas: characterization and its relation to function, and the need for high resolution surface measuring instruments.

\subsubsection{Surface Finish and Automobile 011 Consumption}

Automobile motor manufacturers have reponded to an accelerated need for control of oil consumption in motors by developing precise and refined criteria for cylinder wall, piston, and piston ring surface finish. The development of thin walled blocks, increased periods between oil changes, air pollution controls, and most recently, the oil shortage, have served as strong incentives for studies of oil consumption.
Prior to the oil consumption studies, the surface finish was specified only in terms of the roughness height (AA or RMS) of the cylinder wall surface. The more recent studies have shown that the boring and honing operations in automotive cylinder manufacture are crucial in controlling oil consumption. While most of these studies are proprietary, a leading manufacturer set up the following specifications for a honing finish in 1964: 1) The honing process should generate a cross hatch pattern of the cylinder surface with a cross hatch angle of $44^{\circ}$ to $64^{\circ}$.

2) It should uniformly cut in both directions.

3) It should be clean cut, not sharp and free of torn and folded metal.

4) The $A A$ roughness should be between 20 and 30 microinches, and should in no case be less than 15 nor more than 35 microinches.

5) The cross hatch should have a average width of $0.0004 "$ - $0.0006^{\prime \prime}$.

6) The cross hatch should have an average depth of $0.00015^{\prime \prime}-0.00025^{\prime \prime}$.

7) The plateau should be $1 / 2$ to $2 / 3$ of the surface.

8) The surface should be free of burnish or glaze and imbedded particles.

While the basic requirments of close piston ring to cylinder wall fit are very important, the above requirements are designed to insure a lubricant retaining surface with enough oil for good lubrication without excessive oil consumption.

The finish of cylinder walls is inspected by a replication process and photomicroscopy. A cross-section of the finish is obtained by cutting out a piece of the cylinder bore, copper and chrome plating, polishing the section and taking photomicrographs at $500 \mathrm{x}$ magnification. Since this is a destructive test, is has limited use. Other studies used stylus instruments and peak counters in evaluating cylinder wall surfaces. The importance of this problem is evident from the $\$ 5$ bizzion yearly product value of automobize motors (Statistial Abstracts of U.S., 1972) and the finish related oil consumption.

\subsubsection{Efficiency of Electric Motors}

A major source of controllable power loss in electric motors involves tiny electrical shorts in the stator laminations. It has long been known that surface roughness plays an important role in controlling these losses but only recently has the proper characterization factor been discovered. Prior to this discovery the only way to determine if a stator assembly had excessive core losses was to build up the laminated stack, weld it together, and then decarburize and anneal the assembly. Only after this manu- 
facturing process was completed could a core loss inspection be performed on the stator assembly.

Engineers had suspected for years that the finish of the laminations was at fault, since if the steel has too smooth a surface, then gases involved in the decarburization process could not pass evenly between the laminations because of the excessive surface contact.

This results in lamination welding, and thus shorts. On the other hand if the surface finish was too rough, the interlocking peaks and valleys between opposing laminations resulted in local shorts. Traditional roughness measurements proved to be inadequate so other means of characterizing the surface were sought. After considerable study it was found that peak counting techniques could be used for quality control of the laminations.

It was determined that a peak count of 150 peaks per inch a 0.030 inch width cut off, and a 50 microinch band width setting was the minimum acceptable level for adequate quality control. A higher peak count is desirable. Surface roughness limits were set between 60 and 125 microinches. Incoming lamination steel must now meet these specifications. The total value of electric motors and generators produced in the U.S. exceeded $\$ 2.5$ billion in 1970 and is rapidy growing (Statistical Abstracts of the U.S. - 1972).

This success story represents the "tip of the iceburg", in that a similar determination of the relationship between proper characterization of a surface and its function could save untold millions of dollars in industries where surfaces are over specified because they are improperly characterized.

\subsubsection{Shaft and Radial Lip Seal Surface Finish}

There are few people in the United States who have not been inconvenienced by a seal failure. For example the author has had a clothes washer transmission seal fail with the consequent loss of the transmission; a dishwasher face seal failed allowing water to enter the electric motor, causing it to short permanently; a water pump seal failed requiring pump replacement, two automobile whee 1 seals leaked causing the brakes to lock, a potentially dangerous situation; a differential seal failed, necessitating replacement of the differential and a rear main bearing seal leaked, requiring an expensive repair. Shaft and radial seals are used in chemical pumps, high pressure pumps, hydraulic pumps and a variety of other devices.

The problem of shaft and radial lip seal design is discussed in great detail by James Symons, General Motors Corp., in an article entitled "Shaft and Radial Lip Seal Performance" (Proceedings of International Conference on Surface Technology, Pittsburgh, $\mathrm{Pa}$. , May 1-3, 1973, page 584). In his introduction, Mr. Symons points out that the surface finish of the shaft is an important parameter in seal performance and reliability. Figure 9 from Symons article shows that the friction between a surface and synthetic rubber depends on surface roughness.

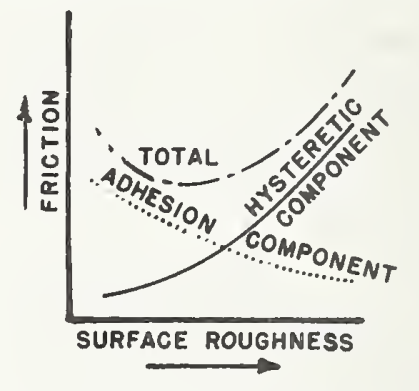

Figure 9: Synthetic rubber friction theory

The adhesion component decreases with increasing surface roughness since it is dependent on the contact area. As surface roughness increases, the contact area decreases and hence friction decreases. The hysteres is component is just the reverse, with increasing surface roughness causing increasing deformation and higher friction due to hysteresis losses. The combined action results in a minimum about where the two curves intersect, the effect is demonstrated in table 2 from Symons for a four inch seal on a plunge ground shaft of 5, 15 and 35 microinches AA surface roughness.

Table 7: Dependence of seal torque on surface roughness.

\begin{tabular}{|c|c|c|}
\hline $\begin{array}{l}\text { Surface Roughness } \\
\text { Microinch } A A\end{array}$ & $\begin{array}{l}\text { Torque } \\
\text { in-oz }\end{array}$ & $\begin{array}{c}\text { Shaft Speed } \\
\text { RPM } \\
\end{array}$ \\
\hline $\begin{array}{r}5 \\
15 \\
35\end{array}$ & $\begin{array}{l}41.2 \\
18.7 \\
30.0\end{array}$ & $\begin{array}{l}1000 \\
1000 \\
1000\end{array}$ \\
\hline
\end{tabular}

Further investigation indicates that $A A$ roughness is not the only surface finish factor which is important, as also shown in 3.1.1.5. The manufacturing process must also be carefully specified. Thus, in seal practice as in other areas, it is the characterization which is lacking in a proper description of the surface requirements. Table 8 lists the replacement cost for the seals in a medium priced American automobile and estimates total yearly sea 1 cost for U.S. manufactured automobiles at $\$ 200$ million. 
Table 8: Cost of individual seal in U.S. manufactured cars and estimated total yearly cost.

Transmission seals

$\$ 3.00$

Rear wheel seals

1.00

2.60

2.50

Crank: front and rear seals

2.00

7.00

8.00

Axle seals

Cost of Manufacturing Shaft Surface

$\$ \overline{25.10}$

Total estimated cost/car

$\$ 210,000,000.00$

Manufacturer Yearly

3.1.1.8 Paintability of Surfaces - New
Powder Coatings Powder Coatings

A new technology has quite suddenly sprung from limitations and problems associated with the traditional painting process, a $\$ 2.9$ billion metalcoating industry. Stemming from an ecological concern over the huge quantity of toxic solvents released into the atmosphere each year, the rapid development of powder coatings has been spurred on by the obvious advantages of a tough, chemically resistant, mechanically stable coating with excellent adherence and abrasion resistance that can be applied in films. which are only 500 microinches thick. The economic advantage of such thin coatings is particularly attractive.

The new powder coatings are electrostatically sprayed onto the surface, usually without a primer, and then heated to spread and polymerize. Epoxies, polyesters, acrylics, vinyls, pholyethylenes, butyrates and nylons are all available, each with particular advantages. The service temperature range of these coatings is from $-370^{\circ}$ to $250^{\circ} \mathrm{F}$ dry and from $-100^{\circ}$ to $150^{\circ} \mathrm{F}$ wet. An article in Iron Age (June 21, 1973) estimates that 250 million pounds of dry powder coatings may be used yearly be 1980 .

New technology, however, is not wi thout its problems. The surface finish of a metal1 ic part determines the appearance of a coated surface, particularly when the coatings are only 500 microinches thick. In measuring the surface panels of automobiles for example the surface finish for wet coatings must be 20 to 30 microinches AA plus a certain (proprietary) distribution of peak counts. The new coatings do not have the desired surface texture when the panels meet these specifications, and new means of characterizing the surface roughness and its relationship to dry powder coatability are being sought by the automative, furniture and appliance industries. The future of this rapidly growing industry may well depend on our ability to manufacture and measure the necessary improved surfaces. NBS interacts with the users of these products, particularly with regard to the characterization problem.

\subsubsection{Electroforming - Duplication of Highly Finished Surface}

Considerable care and expense is usually required to manufacture very smooth surfaces, or surfaces with a precisely defined texture. Electroforming is an electrochemical process of metal fabrication involvina the duplication of an original artifact, for example a precision reference specimen of surface roughness, without the aid of mechanical forming, machining, welding, grinding, etc. The technique uses an electrolyte, an anode

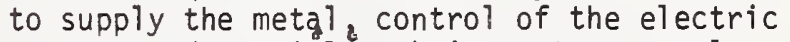
current and special techniques to control the deposit of metal on the madrel (form) which is to be duplicated. The surface finish of the duplicate conforms to the original within a microinch $A A$ and dimensional tolerances can be held to 100 microinches. Typical electrodeposited metals include copper, iron, silver and nickel.

Electroformed articles often have difficult shapes to manufacture, inside surfaces which are highly polished or surfaces with a highly controlled texture. Optical reflectors which are nearly perfect copies of the original are an excellent application of this technique. Radar waveguides which have extremely smooth interiors, surface comparators with carefully controlled texture, tiny tubing with polished bore, nickel ice augers, prototypes for cosmetic containers and diffraction gratings are among the many products manufactured by electroforming.

The ability of the electroforming process to duplicate the original surface is exploited in the manufacture of precision reference specimens where the first duplicate of the master is carefully measured for surface roughness. The extreme fidelity with which the surface is reproduced enables one to safely assume that all succeeding duplicates have the same roughness within the accuracy of the measurement system, with only occasional recalibrations.

The chief sales engineer for the leading electroforming company among the 28 independent companies estimates that the yearly product value of the U.S. electroforming industry may presently be as high as $\$ 100 \mathrm{mil}-$ lion. In addition, the big automotive companies also operate electroforming plants, as do a few other large corporations. 


\subsubsection{Surface Requirement in the Elec- tronics Industry}

In the last two decades a huge industry has developed from the invention of the transistor and other semiconductor devices. Today, thin film devices manufactured on ceramic substrates are presenting new and challenging measurement problems in surface finish. An article by R. C. Sundahl and L. Berrin of Bell Laboratories ("Surface and Subsurface Analysis and Characterization", Preceedings of the Symposium on the Science of Ceramic Machining and Surface Finishing, Gaithersburg, Md., November 2-4, 1970) describes the need for proper characterization, and related measurement problems associated with Ceramic surfaces. They point out that, "The analysis and characterization of surface resulting from ceramic forming, machining, and finishing methods are necessary to obtain a fundamental understanding of the effects of such operations on surface properties. It is through this understanding that ceramic surfaces can be improved so as to meet the rigid requirements of new technologies."

A typical silicon integrated circuit package provides a 1,024 bit IGFET (insulated gate field effect transistor) memory on an $80 \mathrm{~mm} \times 30 \mathrm{~mm}$ by $1 \mathrm{~mm}$ thick ceramic substrate. (Since the electronics industry uses metric units this practice will be reflected in the present discussion). Photolithographic techniques are employed in this vapor deposited metallization process whereby electrical leads 5 micrometers wide spaced 10 micrometers between centers connect the active elements. One 5 micrometer imperfection in the surface can cause either an open or a short circuit. Excessive surface roughness, scratches, pits, etc., threaten the integrity of the finely detailed interconnect patterns.

These surfaces are examined with stylus instruments, optical microscopes and scanning electron microscopes. It is claimed that surfaces are achieved with roughness less than 0.005 micrometer ( 0.2 microinch), which is well beyond the present measurement capability. But the real challenge lies ahead. There is discussion in the industry of devices under development which will employ the switching properties of interlocking molecules on surfaces so smooth that only a few atomic steps $(0.001$ micrometer or 0.04 microinch) could interfere with the reliability of the device. While the electronic component industry has already reached the $\$ 7.5$ billion level (Statistical Abstracts '72), it is clear that future growth could be staggering, particularly if the surface measurement problems do not present a roadblock.

\subsubsection{Summary of Measurement Needs}

In table 9 the author has estimated from his discussions with engineers from each technology and from his knowledge of measurement applications, the impact that an appreciable improvement in resolution, characterization, non-contacting instrumentation, on-line measurement and improved accuracy would have on the quality of product in each of twenty technologies. Specifics are discussed in the previous paragraphs. Clearly, improved characterization is most urgently needed with on-line measurement a close second. NBS efforts to improve characterization will be discussed in section 4.2 .

\subsubsection{Distribution of Surface Finish Instrumentation}

Table 10 lists the distribution of stylus instruments among metalworking industries in the U.S. in 1973 according to the 1969 Standard Industrial Classification Code (SIC).

\subsubsection{Measurement Needs in High Tech- nology Industries}

Among high technology industries, one of the most sophisticated is optical system design and fabrication. Imperfect optical surfaces scatter light and thus degrade the performance of optical instruments. The growing need for improved measurement and characterization of optical surfaces is being met by research scientists at the Naval Weapons Laboratory, China Lake. A11 known optical techniques for measuring surface roughness have been reviewed in an NBS Technical Report abstracted in appendix B.6.

Another important technology, the electronics industry, finds that tiny imperfections on substrate surfaces result in a high rate of device failure. In the computer industry the surface finish requirement for tape recorder heads, memory discs and drums and tape transport devices are presently beyond the state of the measurement art. Microminiaturization also places new demands on surface characterization.

Laser window, mirror, and lens damage is strongly influenced by surface topography. Our ability to make further progress in complex laser fusion devices is limited by several factors, one of which is laser mirror failure when high powered lasers are focussed on the fusion chamber. It has been established that a major source of mirror damage is the high electrostatic field at the mirror surface due to surface imperfections (discussed in several articles in Applied Optics, 
Table 9: Measurement improvement impact matrix: The impact of specific measurement improvements on product quality and quantity is ranked as Low (L), (1ittle effect), Medium (M), or High (H), (considerable impact).

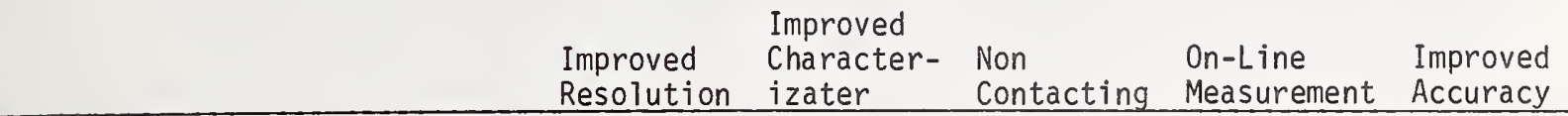

1. Surgical Implants
2. Gravure Printing
3. Dairy Industry
4. Auto 0il Consumption
5. Auto Motor
6. Auto Drive Chains
7. Paintability
8. Electric Motor
9. Semiconductor
10. Prec. Ref. Spec.
11. Ball Bearings
12. Computer Discs
13. Shaft and Lip Seals
14. Surface Science
15. Electrical Contacts
16. Surface Instrument Industry
17. Tin Cans
18. Sleeve Bearings
19. Chrome Plating
20. Optical Surfaces

$\begin{array}{ll}H & H \\ H & H \\ L & H \\ L & H \\ M & H \\ L & H \\ L & H \\ L & H \\ H & M \\ H & M \\ H & H \\ H & M \\ L & H \\ H & H \\ L & M \\ H & M \\ M & M \\ H & M \\ M & M \\ H & H\end{array}$

$\begin{array}{lll}M & L & M \\ M & M & M \\ L & H & L \\ L & H & \text { L } \\ L & H & \text { M } \\ L & H & \text { L } \\ L & H & M \\ L & H & M \\ H & H & H \\ L & L & M \\ M & H & M \\ H & M & L \\ L & H & H \\ H & L & L \\ H & M & H \\ M & M & L \\ L & H & L \\ M & H & H \\ L & H & \end{array}$

spring of 1973). A major unresolved problem in the microelectronics industry involves measuring the topography of the silicon silicon oxide interface in metal-oxide-semiconductor microcircuit devices. The effect of roughness on the mobility of free carriers in the silicon surface layer is well established but the measurement of the inaccessible solid-solid interface represents a new challenge A leading communications industry cannot find an adequate way of characterizing the surface roughness of fiber optics proposed for long range communications (see letter appendix A).

A challenging example exists in the field of thin film lubricants (sometimes involving dry film monomolecular layers) that are being developed for instrument bearings and pivots. Failure of these bearings is directly related to the residual surface roughness of a bearing that has been polished to a mirror finish. An extreme requirement involves the developing field of molecular electronic devices where one-dimensional conductors can be switched to insulators. These devices re- quire that surface roughness be of the order of interatomic distances.

\subsubsection{Economic Impacts - Costs and Benefits}

The largest user of surface texture measuring instruments is the metalworking industry. Table 10 shows the wide distribution of these instruments in industries grouped according to the Government's "Standard Industrial Classification Manual". It is difficult to determine the number of instruments in non-metalworking industries, universities, small companies ( 20 people) and particularly the electronics and high technology industries (for example computer disc and drum memory and optics industries). The sales manager for the largest U.S. surface finish instrument manufacturer estimates that there are at least 25,000 surface texture measuring instmuments in the United States. He reports that total instrument sales in the U.S. average $\$ 2$ mizlion per year. Instruments cost from $\$ 1,000$ to $\$ 20,000$ each with an average replacement 
Table 10: Distribution of surface finish instrumentation - Surface measuring instrument located in metalworking plants grouped into industries according to U.S. Government "Standard Industrial Classification Manual" as of 1968. A11 non-metalworking industries, government-owned installations, universities and plants with less than 20 employees are not included. Data is based on 1973 American Machinist Inventory of MetaTworking Equipment, McGraw-Hill.

1969

SIC

Code Brief Description of Industry

019

025

033

034

035

036

037

038

039

251

252

253

254

259

331

332

333

335

336

339

341

342

343

344

345

346

347

348

349

351

352

353

354

355

356

357

358

359

361

362

363

364

365

366

367

369

371

372

374

381

382

\section{Ordnance}

Furniture and Fixture

Primary Metal Industries

Fabricated Metal Products

Machinery, Except Electrical

Electrical Machinery, Equip.

Transportation Equipment

Professionally, Scientific, Optical

Miscellaneous Mfq. Indus.

Household Furniture

Office Furniture

Building \& Related Furniture

Partitions, Shelving, Lockers

Misc. Fixtures

Blast Furnaces, Steel Works

Iron \& Steel Foundries

Primary Smelting and Refining

Rolling, Drawing \& Extruding

Nonferrous Foundries

Misc. Primary Metal Products

Metal Cans

Cutlery, Hand Tools \& Hardware

Heating Apparatus, Plumbing

Fabricated Structural Metal Prod.

Screw Machine Products

Metal Stampings

Coating, Engraving

Misc. Fabricated Wire Products

Misc. Fabricated Metal Products

Engines and Turbines

Farm Machinery \& Equipment

Mining, Machinery \& Equip.

Metalworking Machinery \& Equip. 15

Special Industry Machinery

General Industrial Mach. \& Equip.

Office, Computing Machines

Service Industry Machines

Machinery, non-electrical

Electric Transmission \& Distrib.

Electrical Industrial Apparatus

Household Appliances

Electric Lighting \& Wiring

Radio \& T.V. Receiving Sets

Communication Equipment

Electronic Components \& Access

Misc. Electrical Machinery

Motor Vehicles \& Equipment

Aircraft \& Parts

Railroad Equipment

Engineering, Lab. \& Sci. Instr.

Instr. for Meas. Physical Char.
Percent Total 10 years

Number

$01 d$

471

37

314

1124

3930

996

1103

322

79

2
18

6

11

34

\section{9}

31

42

69

99

13

119

8
184

308

90

216

10

176

177

103

161

711

165

1364

206

51

992

113

189

63

113

6

278

200

34

353

729

16

121

102

308

565

208

7

2
9

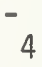

20

28

28

40

63

69

13

51

8
116

237

74

203

10
134

83

48

83

465

102

809

174

38

735

84

121

52

86

3

163

177

27

168

394

2

65
68
Under

10-20

Over 20

Years 01d Years 01d

1103
146

21
55

235

268

470

290

$100 \quad 14$

$45 \quad 27$

9
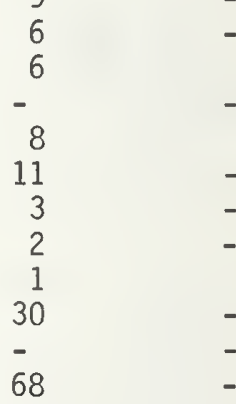

-

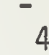

$\begin{array}{rr}170 & 76 \\ 55 & 8\end{array}$

$475 \quad 80$

28
4

$210 \quad 47$

$210 \quad 47$

$56 \quad 12$

11

27

115

23

158

303

5

52

31
17

1

11

43

15

68
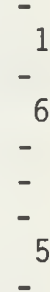

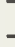

14
24

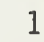

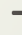

45

13

4

7

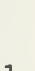

6

5

80

9

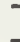

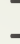

$-$

-

27

32

9

4

7
1
1
43
90
15
68


Table 10 (continued)

1969

SIC

Code

384

386

387

391

395
Brief Description of Industry

Surgical, Medical, \& Dental

Photographic Equipment

Watches, Clocks, Clockwork

Jewelry, Silverware \& Plated

Pens, Pencils \& Materials

Office \& Artists' Materials

\author{
Percent \\ Width
}

15
6
22
3

Tota 7
Under

Total 10 years

Number

old

60

2

5

39

27
10-20
Years 01d 20
Years 01d

$\begin{array}{rr}9 & 1 \\ 2 & 6 \\ 3 & - \\ 32 & -\end{array}$

\section{$\overline{16,253}$}

cost of about $\$ 1,500$. Thus, total replacement cost for all industries is about $\$ 1,500 \times 25,000$ instruments or $\$ 37,500,000$.

So far as can be determined there has been no study of the "value added" by the measurement of surface texture. Assuming all instruments are used only 10 percent of the 8 hour working day the metalworking industry spends about $\$ 50$ milzion in labor and overhead costs a year in surface finish measurement over and above yearly instrument investments of $\$ 2$ million. The dolzar value of products from those industries requiring surface finish measurement, including machine tools, tool products and fabricated metal parts is about $\$ 42.4$ bizzion dozzar today (1973 report of Nat. Mach. Tool Bldrs. Assoc.). Thus, even though the yearly expenditure in surface finish measurements is only one tenth percent of the gross sales of final product, this still amounts to a substantial $\$ 50$ million dollars a year.

Thin film steps are either measured with stylus instruments or with a two beam or a

$10 \mathrm{a}$

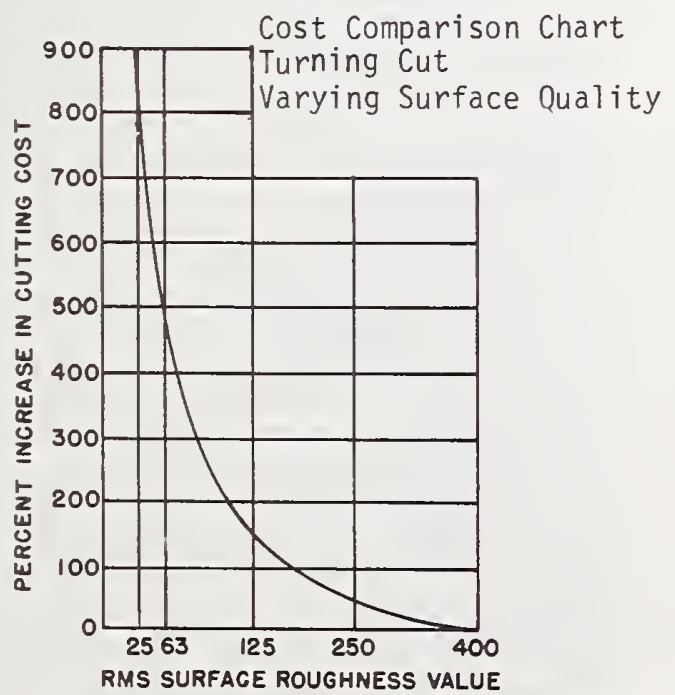

Figure 10: Cost Comparison Charts: milled surfaces multiple beam interference microscope. The product manager for a large microscope manufacturer, estimates that there are about 1000 interference microscopes in the United States. At $\$ 1,000$ each, they represent an investment of $\$ 1$ mizzion. If used $10 \%$ of the working day they represent a labor investment of $\$ 2$ mizlion per year for thin film step measurements.

Precision reference specimens are usually supplied with stylus instruments for calibration purposes. In addition Precision Reference Specimens are sold directly to users. Since all instruments require some sort of calibration, it will be assumed that each existing instrument has at least one precision reference specimen worth about $\$ 75.00$, involving a total capital investment of $\$ 1.87$ mizlion. The economic dimensions of the impact areas are summaried in table 11.

The surface finish of a part is often overspecified either from habit or lack of knowledge. One of the few published studies

$10 \mathrm{~b}$

Cost Comparison Chart

Face Milling Cut

Varying Surface Quality

Varying Tolerance

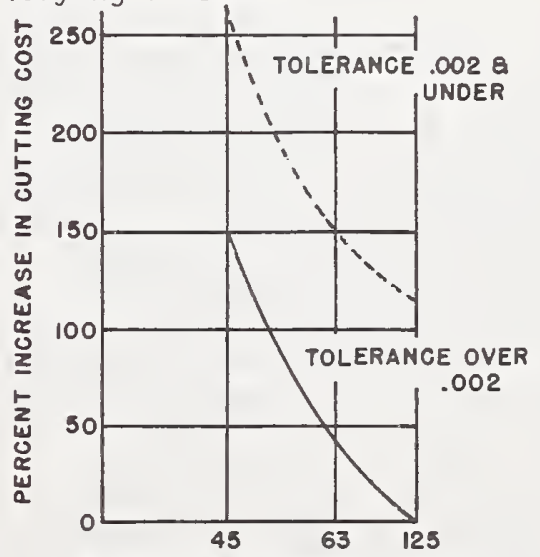

RMS SURFACE ROUGHNESS VALUE

a) turned surfaces, b) face 
Table 11: Economic dimensions of impact areas in surface finish measurement in the U.S. metalworking industry. Top line-first two columns: number of instrument purchased in 1972 and investment cost. Last two columns are labor cost for surface measurements and dollar value of total product involved. The lower three lines involve total instruments and total costs. See text for source.

\begin{tabular}{|c|c|c|c|c|}
\hline & $\begin{array}{l}\text { Number of } \\
\text { Instruments } \\
\text { or Specimens } \\
\text { Purchased }\end{array}$ & $\begin{array}{l}\text { Industrial } \\
\text { Instrument } \\
\text { Investment } \\
\text { Cost }\end{array}$ & $\begin{array}{l}1972 \\
\text { Industria1 } \\
\text { Labor Cost } \\
\text { (measurements) }\end{array}$ & $\begin{array}{l}1972 \\
\text { Dollar Values } \\
\text { of Total } \\
\text { Product Affected }\end{array}$ \\
\hline $\begin{array}{l}\text { Stylus Instruments } \\
\text { a) } 1972 \text { only } \\
\text { b) Total Number in } \\
\text { Use. }\end{array}$ & $\begin{array}{r}1,300 \\
25,000 \\
\end{array}$ & $\begin{array}{l}\$ 2 \text { Million } \\
37 \text { Million }\end{array}$ & $\$ 50$ Million & $\begin{array}{c}\$ 42.4 \text { Billion } \\
---\end{array}$ \\
\hline $\begin{array}{l}\text { Interference } \\
\text { Microscopes } \\
\text { Total Number } \\
\text { In Use } \\
\end{array}$ & 1,000 & 1 Million & 2 Million & --- \\
\hline $\begin{array}{l}\text { Precision } \\
\text { Reference } \\
\text { Specimens }\end{array}$ & $\begin{array}{c}25,000 \\
\text { (estimated) }\end{array}$ & 1.9 Million & $\begin{array}{l}\text { See stylus } \\
\text { instruments }\end{array}$ & $\begin{array}{l}\text { See stylus } \\
\text { instruments }\end{array}$ \\
\hline
\end{tabular}

of the relationship between surface finish and cost is illustrated in figures 10a and b (Lad J. Boyer, Warrer and Swarsey Co., American Society of Mechanical Engineering paper \#56-SA-9, June 1956). From figure 10a it is seen that improving the surface finish of a turned surface from 50 to 25 microinches almost doubles the turning cost. Similar conclusions are reached from the study of milled surfaces, figure $10 \mathrm{~b}$ and ground surfaces (see Bayers paper). Thus, there is usually a compromise between the economics of part manufacture and the ability of the part to function properly and have an acceptable life expectancy.

\subsubsection{Social, Human, Person-on-the Street Impacts}

The impact of surface measurement on the person-on-the-street has been discussed at length in section 3.1.1. Much of the impact of surface finish is cosmetic and spans the range from automotive bodies and milk storage tanks to jewelry. Safety considerations are most evident when a wheel bearing fails in an automobile or a wheel seal permits oil to reach brake drums causing the wheels to lock while braking the car. People with surgical implants, such as hip joints, place their trust in the manufacturer who provides highly polished alloy balls, hopefully with lifetimes reaching ten years. As discussed in 3.1 .1 , surface finish plays an important role in sterilization and sanitation. A well finished surface eliminates sites for bacterial growth and permits rapid inspection of the surface. Thus, all surgical, dental, hospital, and food handling surfaces are careful finished.
A list of national issues and related surface measurement needs is given in table 12 .

\subsection{Status and Trends of the System}

The calibration system for surface roughness and thin film steps is functioning in accordance with the standard (B46.1). NBS performs calibrations at the highest level available in the U.S.; calibration turn around time is 30 days. Secondary laboratories have not requested improved accuracy, although certain high technology industries request calibrations at smaller AA values. At NBS's request, the need to improve the flatness and quality of U.S. precision reference specimens will be addressed in the revised standard. There is need for a specimen with surface roughness values below 20 $\mu$ in $(0.5 \mu$ meter $)$, the smallest value available on U.S. specimens. Thin film step measurements will improve as the quality of the surfaces near the step is improved. Metric terminology will be introduced in the revised standard.

U.S. engineers and scientists exercised strong leadership in the early development of surface finish instrumentation. Unfortunately this leadship has been minimal during the last 10 to 20 years so that most of the recent innovative work in characterizing surfaces has come from abroad. A study of the literature reveals that England, Germany, Japan and the U.S.S.R are particularly active. A German company manufactures instruments which measure a variety of surface roughness parameters and a British company markets computerized instruments measuring many parameters. 
Table 12: Surface measurement needs related to some present day national issues

National Issues

Defense

Energy

Materials

Health and safety

World trade

Productivity

Agriculture

Communications
Related surface measurement needs

- upgrading of characterization; sensitive, non-contacting instrumentation needed for classified applications (this need is not documented here)

- high resolution measurement for laser fusion mirrors (energy generation)

- development and measurement of single-crystal surfaces

- discussed in 3.1.1 - higher resolution for surgical implants, improved bearings and seals, better characterization of food handling and sanitary surfaces

- participation in ISO standards formulation to prevent discrimination against U.S. exports

- determination of least expensive surface finish which is adequate for function. This work is difficult and expensive but has great economic leverage

- dairy and food handling industry is investigating improved characterization of sanitary surfaces

- integrated circuits and microelectronic devices require unrealized measurement of single atom steps

Some segments of the industrial community are very aware of the surface characterization problem. For example, the leading manufacturer of industrial polishing materials, at a recent visit to NBS said, "American industry is being penalized in areas where standards are tied to a particular manufacturing process rather than properly characterizing the needed finish. Such standards result in an inflexibility in procurement and inspection procedures so that use of new materials and manufacturing processes, which are often superior and less expensive than traditional processes, are prohibited. The problem is particularly acute in foreign markets where local standards are more responsive to changing technology, resulting in an unfair market disadvantage for the U.S." Examples of this problem included dairy surfaces, hydraulic pistons, seals, and bearings.

The recent development of the stylus/computer calibration system at NBS makes full parameter measurement available in the U.S. However, it is necessary that users have instrumentation close at hand to make such measurements and that they carry out development programs to study the relationship between finish and function.

A number of high technology needs have been discussed in 3.1.1.13. Perhaps the most challanging requirement is for measurement of single atom steps in applications such as molecular microelectronic devices, surface science studies of single crystal surfaces and microminiaturization components. NBS is developing an instrument to meet these needs.
The scanning electron microscope provides the highest resolution direct images of solid surfaces $(10 \mathrm{~nm})$. It is characteristic of the instrument that it has extremely poor vertical resolution so that the profile of a surface may not be measured with accuracy greater than $150 \mathrm{~nm}$. Very high priority should be given to the development of new techniques for profile measurements with this instrument.

The major impact of automation on the surface finish measurement system is the need for on-line non-contacting surface finish measuring instruments. A number of instruments are under development in U.S. to fill this need.

\section{SURVEY OF NBS SERVICES}

\subsection{The Past}

Throughout the first half of this century, NBS scientists have been active in a variety of areas related to surface finish measurement. Several aspects of this early work were focussed in a 1946 NBS Research paper (RP 1708) by Richard Hunter comparing measurements made with an NBS developed glossmeter with those made with a stylus instrument. Little is known about NBS surface finish calibrations per se prior to World War II. In the early fifties some calibrations were carried out but it was not until the 1955 American National Standards Institute B46.1 standard on surface texture was approved that such measurements became routine calibrations. Until then, there was no uniformly accepted measurement procedure. By late 1955 work at NBS had reached a stage of 
sophistication enabling NBS to measure and discuss critically the roughness of highly finished gauge blocks (Symposium on Gauge Blocks, NBS, Aug. 1955). In the 1960's NBS developed and tested a piezoelectrically activated shaker table for calibrating stylus instruments over their full range of frequency response. This work was discontinued when the scientist in charge left NBS.

The present standard developed when the American Standards Association authorized a joint effort by the American Society of Mechanical Engineers and Society of Automotive Engineers in 1932. After exhaustive studies, drafts, meetings, ballots, etc., three successively upgraded documents were approved in 1947, 1955 ( similar to today's standard) and 1962 (compatible with Great Britain and Canada). The present standard is now under revision. NBS staff members were deeply involved in developing these standards and are writing parts of the new document and carrying out experimental studies to refine the section on instrument and measurement requirements.

NBS impacts directly on a variety of industries by carrying out special studies of surface topography in expecially challenging areas such as the topography of plastic coated surfaces, semiconductor surfaces and dri11 bit cutting surfaces.

\subsection{The Present Scope of NBS Activities}

\subsubsection{Description of NBS Services}

Al1 surface roughness and thin film step measurements and calibrations are carried out in the Optics and Micrometrology Section of the Mechanics Division (Institute for Basic Standards). Precision reference specimens and quality thin film steps are calibrated relative to the defined unit of length and in accordance with the national standard for surface texture. Special studies are carried out for particularly challenging surfaces on a fee basis. A variety of surface characterizing parameters are computed from the surface profiles. In addition to fee supported calibrations, NBS maintains a technical base through internally funded studies and instrument development programs, and also coordinates the national measurement system for surface finish through dialogues with users and participation on standards committees .

Although NBS has frequently been requested to participate in the formulation of international standards in order to protect American industry from arbitrary and discriminatory international standards, personnel, funding and travel limitations prevent such participation.

NBS is very active in The American National Standards Institute activities in generating and revising standards. One staff member is on Committee B46, the policy making group, and another is a member of B46.5, a subcommittee revising the 1962 standard.

NBS has just completed a report to users explaining the new NBS measurement system which employs a mini-computer to store 4,000 profile points from a stylus instrument, and then calculates the AA roughness value. The system is calibrated before each use with an interferometrically calibrated step, which makes the measurement traceable to the standard of length. The new system, which was initiated in July, 1973, resulted in at least a two-fold increase in accuracy (see fig. 7). Furthermore, the computer can also be used to calculate any of the other surface characterizing parameters discussed above for any surface. To date U.S. instruments have not been equipped to measure these other parameters, with the exception of peak counting, in spite of the availability of such instruments abroad. The calibration of thin film steps is discussed in 2.2.2.1 (see fig. 8). Optical instruments are also used at NBS in surface roughness measurements. The most refined stylus instrument, capable of detecting surface structure as smal1 as $10 \mathrm{~nm}$ with horizontal resolution of 1 micrometer, is employed in $u 1$ trasensitive measurements.

NBS is presently developing a high resolution non-contacting instrument for measuring surface topography (see Appendix B.7 and B.8). This instrument employs the novel concept of following the profile of the surface with a field emission probe, enabling drastically improved horizontal and vertical resolutions (10 $\mathrm{nm}$ and $0.3 \mathrm{~nm}$ respectively) which permits measuring single atom steps. Another development program exploits the two beam microinterferometer and a precision scarining microdensitometer to obtain accurate profiles of surfaces without damage from surface contact. As far as can be determined NBS is in communication with every established U.S. and most foreign leaders in surface metrology. A list of the users who were consulted in the preparation of this assessment together with a few sample letters from high technology users are included as Appendix A. The more important NBS contributions 


\section{INPUT}

\begin{tabular}{l}
\hline GOVERNMENT \\
\hline NASA \\
MIL Specs \\
Defense Agencies (Metrology Labs) \\
Postal Service \\
Lawrence Livermore Lab \\
NBS/Toy Safety Program \\
NBS/Electronic Technology Div.
\end{tabular}

\section{INDUSTRY}

Surface Finish Instrument $\mathrm{Mfg}$. Precision Reference Specimen Mfg.

Optical Instrument Mfg.

Defense Related Industries

Precision Mechanical Instrument Mfg.

STANDARDS GROUPS

Internationa 1 Standards Org.

American National Standards Institute

American Society of Testing and Material

JOURNALS

Microtechnic

Mechanical Engineering

American Machinest

NBS Journal of Research

Measurement Techniques

Wear

Inst. of Mechanical Engineering Journal of Physics

J. Optical Soc. Amer.

Applied Optics

SOCIETIES AND INSTITUTIONS

Amer. Gear Mfg. Association

Amer. Soc. Mfg. Eng.

Amer. Soc. Tool Eng.

Amer. Ord. Association

Int. Inst. for Prod. Eng. Research

Dairy and Food Ind. Association

Amer. Soc. for Metals

Amer. Soc. Mech. Eng.

Soc. of Automotive Eng.

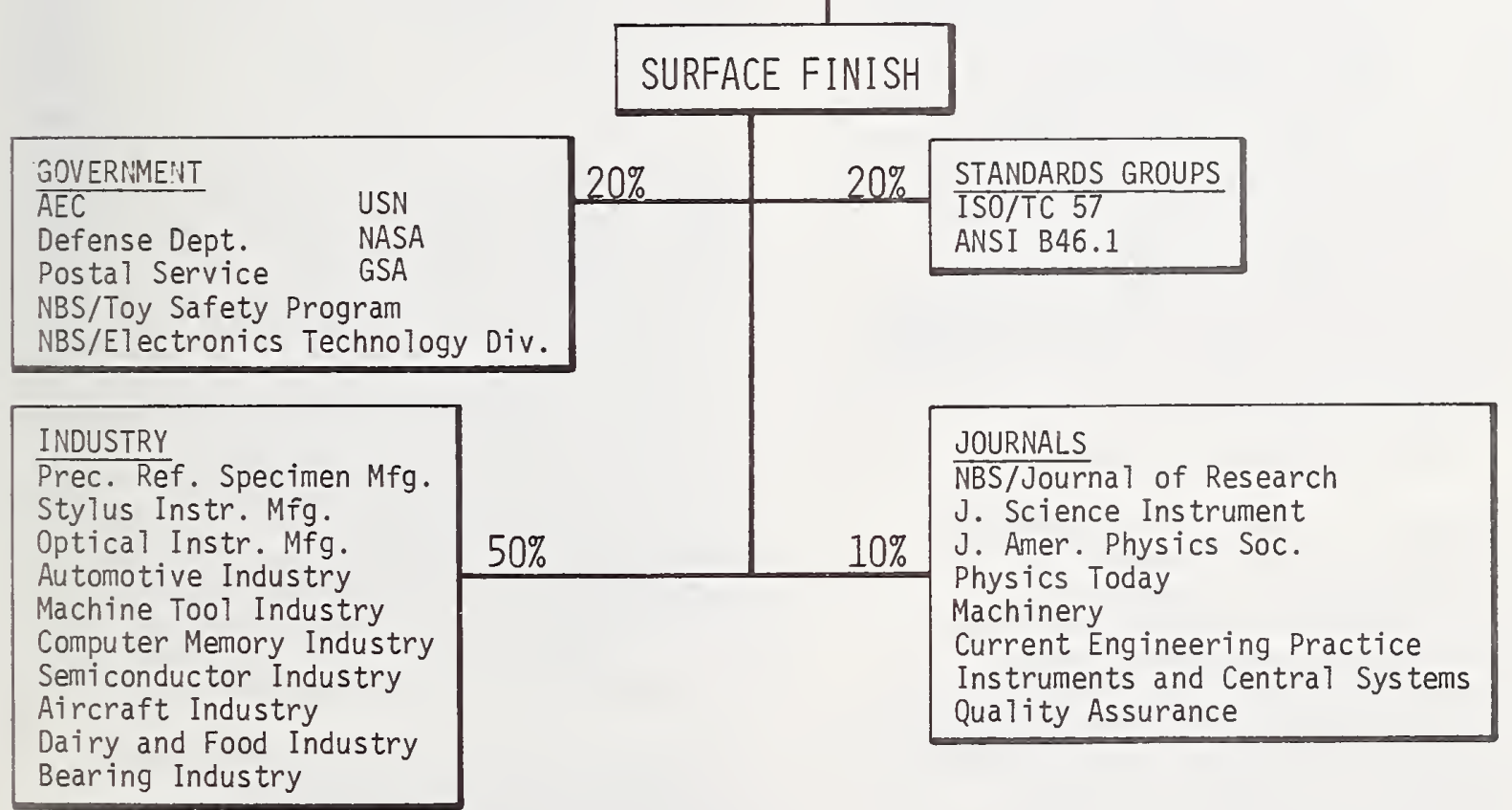

\section{OUTPUT}

Figure 11: NBS Information and Calibration Input-Output Chart 
to the surface literature in the last

few years are summarized in Appendix $B$.

One of the most effective ways of determining the integrity of a measurement system is through intercomparisons, where a blind round robin is conducted with other users. NBS is presently involved in an American Society of Mechanical Engineers round robin on Scratch and Dig Standards for optical surfaces which will also include optical measurement of surface roughness by light scattering. The danger always exists that artifacts circulated in such a round robin will become de-facto standards of "optical surface roughness" which are unrelated to the national standard. A second round robin is in progress for one segment of the National Conference of Standards Laboratories. A third proposed but as yet uninitiated intercomparison would involve the U.S., Canada, England, Australia and Germany. With reference to the Input-Output Transactions Matrix (table 6) NBS provides a full spectrum of services to the industrial/scientific community ranging from highly sophisticated special studies, calibrations of precision reference specimens, technical and semi-technical publications, conferences, telephone and in-person advice, joint studies with universities and industries, standards committee work, to responses to mundane problems such as measurement of the roughness of wallpaper and cast surfaces. Figure 11 is an NBS Information and Calibration Input-Output Chart listing the sources of information, technology, challenging measurement problems, and scientific base for surface metrology, as well as the distribution of effect in terms of calibrations, special studies, consultations, publications and contribution to Standards Committees.

\subsubsection{Users of NBS Services}

The users of NBS surface metrology facilities include all segments of the metalworking community, as detailed above, the various metrology laboratories concerned with length metrology, instrument manufacturers, the various defense and space agencies, the electronics industries and standards associations. All of these users have been discussed above. All are interested in maintaining a viable measurement system to insure the orderly transfer of goods and services. Some have special problems requiring sophisticated or as yet unattainable measurements.
Many are interested in improving their products or lowering costs by determining the relationship between surface finish and part function.

\subsubsection{Alternate Sources}

There are no alternate sources of primary calibrations of surface roughness in the U.S. Highly accurate secondary calibrations are available from a variety of instrument manufacturers (see Table 3).

\subsubsection{Funding Sources for NBS Services and Distribution of Effort}

Personnel - 1 Ph.D. (1/3 time); 1 M.S. (ful1) 1 Physical Science Technician (ful1)

Yearly Budget-................ \$84,000 1974 Calibration effort (reimbursed) $\$ 12,000$ (excluding internal services)

Thus, the ratio of NBS expenditures for surface measurement $(\$ 84,000)$ to the metalworking industry expenditures for labor and instrumentation ( $\$ 54$ Million) is $1 / 640$ or less than $0.2 \%$.

Effort Distribution

Calibration (including internal services) $15 \%$ Improving quality of calibrations $\quad 50 \%$ Instrument development 20\%

Standards committee work $5 \%$

This study 10\%

$100 \%$

Limited NBS manpower for surface metrology prevents achievement of important goals such as 1) preventing discrimination against U.S. manufacturers in International Standards by active participation in generating these standards, 2) development of instrumentation for refined measurements such as those for surgical implants and semi-conductor device surfaces, 3) exercising leadership in relating surface finish to part function thru new means of surface characterization and 4) development of instrumentation to broaden the usefulness of the scanning electron microscope in surface profile measurements.

\subsubsection{Mechanism for Supplying Services}

Services are provided thru calibration of precision reference specimens, publications, talks, correspondence, standards committees and personal interactions with users. 


\subsection{Impact of NBS Services}

\subsubsection{Economic Impact of Major User Classes}

The economic impact of users was discussed in 3.1.2, including dollar value of measurements and instrument investment, social impact, etc. No way has been found to estimate the impact of withdrawing NBS surface calibration services, although it is clear that the major effects would not be evident for many years.

\subsubsection{Technological Impact of Services}

Technological impact has been discussed in 3.1 .

\subsubsection{Pay-off from Changes in NBS Services}

NBS instituted a new calibration system in 1973-4 which improved accuracy and permitted the measurement of a variety of surface characterizing parameters. The impact of this drastic change in services has not yet been fully felt. Perhaps the least appreciated advantage of proper characterization is the manufacturing cost reductions which can be achieved. The sales manager for a leading surface instrument manufacturer pointed out, "overfinishing of parts is very common due to a lack of knowledge as to the required surface finish for the intended function. Surface finish is frequently specified from habit." When a problem arises which is believed to be due to surface finish, the response usually is to tighten the $A A$ roughness specifications rather than attempting to relate the function to an appropriate characterization of the surface. Now that improved characterizing parameters are available it is hoped that cost reductions will be achieved. Other pay-offs have been discussed above. Unfortunately, many of the specific pay-offs for special studies conducted by NBS are company proprietary and cannot be reported here.

\subsection{Evaluation of NBS Programs}

As discussed in 4.2.4, the overal1 U.S. position in surface finish measurement and in quality and cost of finished parts would be enhanced if the surface characterization program were expanded from $21 / 3$ to $31 / 3$ man years/year. The new instruments developed and calibrated would serve a variety of high technology users. Participation in ISO would help protect U.S. manufacturers in foreign trade as shown above. On the positive side, NBS now has the most accurate and sophisticated surface calibrating and measuring instrumentation available to users in the U.S. and, as far as can be determined, in existence in the U.S.

The industrially based Advisory Panel of the Optical Physics Division has traditionally had at least one member, and typically two, who have had a primary interest in surface finish. These members are invaluable sources of information, insure contact with industry and exert a guiding influence over the surface metrology program. After careful study, the panel as a whole has supported and encouraged NBS programs to develop new surface instrumentation.

In surface metrology at NBS, calibration of precision reference specimens for outside users has priority over al1 other work with turn around times of 30 days. Second priority is assigned to special studies for industrial users. Remaining activities in priority order include calibration for users within NBS, upgrading calibration instrumentation, talks, seminars and standards committee meetings, and $\mathrm{R}$ and $\mathrm{D}$. Calibrations are monitored by means of a monthly calibration computer printout to the section chief listing all items submitted for calibration, the items completed, and those in-process. Performance of primary calibrations are 1 imited to NBS, since at the moment, no other testing or metrology laboratory has the measurement capability available at NBS and users express their desire to deal with an impartial, independent calibration $1 a b$.

\subsection{The Future}

\subsubsection{Driving Force for NBS Programs}

The three most pressing future requirements in surface finish are (1) improved characterization of technically significant surfaces through the use of new parameters, (2) improved resolution and (3) non-contacting instrumentation. It is clear from Appendix B.7 that there is no obvious path to improved resolution. Figure 3 suggests that molecular electronic devices are anticipated by 1980 . These devices require a substrate which is flat on the atomic 
level. To achieve this goal, improved resolution is essential. Integrated circuits, microminiaturization, surgical implants, computer discs and drums, laser fusion mirrors, diesel engine bearings, gravure printing cylinders and a host of other technologies, many listed in above sections, require improvement in accuracy, sensitivity and characterization of surface finish. One of the most desirable solutions to these problems is to develop new concepts in extracting profile information from scanning electron microscopes. This problem is presently under informal study at NBS.

It is clear that advantages associated with non-contacting, rapid, optical techniques for in-process surface finish quality control will receive increased use. Calibration, however, remains a problem. The difficulties involved are discussed in the internal NBS report summarized in Appendix B. 6 .

The rapidly expanding field of surface science has encountered a technological barrier in generating and characterizing singlecrystal surfaces which are smooth on the atomic level. Theoretical understanding of experimental results requires the precise characterization of single-crystal surfaces. Thus, a whole technology of single-crystal surfaces, parallel to the development of bulk single-crystals, is emerging. Characterizing these surfaces on the atomic level is a severe challenge. Such surfaces may open the door to new devices, corrosion resistant surfaces and special instruments and standards. (See Appendix B.7.)

The need to develop precision reference specimens with smaller AA roughness values (20 microinches and less) has been suggested in 2.2.2.1. Thin film deposition techniques and photomask fabrication are possible approaches to high quality low roughness surfaces.

\subsubsection{Alternative NBS Responses to Surface Measurement Needs}

In the following paragraphs four measurement problems will be outlined together with a number of possible responses and the present recommendations based on available resources. Recommended reprogramming will be indicated.

Some of the major considerations (documented above) in evaluating alternatives are:
1. The largest U.S. instrument manufacturer grosses only $\$ 1$ million per year in surface finish instrumentation even though users have a $\$ 37$ million investment in these long lived instruments. This gross income is insufficient to support an R and D program in surface characterization.

2. As seen from table 10 , the users are distributed extremely widely throughout the U.S. industry, large and small, so that few of these industries could consider such an $R$ and $D$ program.

3. Foreign competition is strong since a closer relationship exists between manufacturers and governments in more socialistic countries. Most theoretical and experimental work in surface characterization occurs outside the U.S. (This is the author's judgment based on a reasonably complete file of the surface literature kept on hand at NBS.) In years to come other nations could completely dominate in this area and control technologies which are dependent on improved surface measurements.

4. The demand for improved measurements by the optics, semiconductor, microminiaturization and thin film industries requires a well planned and coordinated effort to develop new instrumentation and techniques.

The four problems mentioned above are listed below together with possible responses and recommendations: a)

a) Calibration of Surface Finish Instrumentation with Precision Reference Specimens; alternative responses:

1. Develop a highly accurate, flexible, dynamic calibrator such as a piezoelectric expander to replace the Precision Reference Specimens.

2. Continue to encourage industry to make improved Precision Reference Specimens by upgrading our ability to measure and characterize them.

3. Do nothing and accept the present system as is.

Recommendation: option 2) since the resources needed for 1) are not presently available.

b) Defining and Testing Surface Characterizing Parameters; alternative responses:

1. Continue to evaluate known parameters, generate and study new parameters and test usefulness of all parameters. Generate facilities and instrumentation for measuring parameters.

2) Continue to upgrade facilities and instrumentation. 
3. Take no initiative in parameter studies.

Recommendation: Mixture of 1 and 2; carry out 2 so that U.S. can catch up to other countries, and seek a post doctoral candidate or an Industrial Research Fellow to work at NBS on the component of 1 concerned with testing the usefulness of different parameters. Both of these programs are presently being implemented.

c) Improved Resolution of Surface Instrumentation: alternative responses.

1. Develop new surface measuring instrumentation with much improved resolution (based on new concepts), as summarized in Appendix B. 8 .

2. Rely on better use of statistical data and computerizing of existing equipment to effect more modest improvement of ins trumentation.

3. Develop optical techniques for measuring surface roughness (see Appendix B.6).

4. Rely on existing systems.

Recommendation: Mixture of 1 and 2. After completion of 2 , which is now in full progress, increase emplas is of 1 , which is now marginally supported. Appendix B.6 discusses in detail the present limitations of optical techniques for absolute measurements. For this reason option 1 should be used to provide an independent measurement of the finish of optical surface.

d) Scratch and Dig Standards of Optical Surfaces. These standards are under revision by an ASTM Committee and may be sufficiently well defined in the new standard so that NBS should consider providing a calibration service; alternative responses:

1. Participate fully in developing the new standard and provide follow up calibration service.

2. Participate peripherally in developing the standard but provide calibration after standard has been approved.

3. Participate through comparison of optical measurements of scratch and dig standards with out non-optical techniques and promote a non-optical calibration sys tem.

4. Do not get further involved. Recommendation: Undecided, the matter is now under consideration. Reprograming may be required unless the staff can be increased. It is not clear whether the new committee will deal effectively with the measurement problem.

\section{SUMMARY AND CONCLUSIONS}

The National Measurement System for Surface Finish appears to be under satistactory control. There is a broadly based need for developing a variety of parameters to characterize surface roughness, and to determine the relationship between these parameters and the function of the part. There is need for improved resolution of surface finish measurements in a number of areas. A noncontacting, on-line instrument for quality control application is in great demand.

While it is extremely difficult to calculate value added by surface finish measurement processes, it is estimated that the metalworking industry alone spends about $\$ 50$ Million in surface measurements each year in the manufacture of $\$ 40$ Billion worth of product. Surface finish measurement is ubiquitous, pervading most industries.

NBS is in good contact with all segments of the measurement community in surface finish. As a result of this study, the characterization of surfaces has been given a high priority, second only to our calibration service. Once the calibration and characterization programs are well in hand, emphasis will be placed on the clearly documented need for advanced instrumentation in certain growing, high technology industries. 
Appendix A: METHODOLOGY OF THE STUDY

A.1 Literature Survey - A complete file of the literature in the field is maintained at NBS in a series of "O-Ring" binders. This literature was evaluated and used as a base from which this study was generated.

A.2 List of People Consulted in Preparing This National Measurement Study (as of 1973). A. People consulted through personal contact either at NBS or at their place of business:

1. Bell Telephone, Columbus, Ohio - Frank Badger, Chris Lo, Rudolph Schubert - the role of surface roughness in quality of electrical contacts

2. Newark Air Force Base - Metrology Labs Chief, Ken Forrer - 29 people calibrating for Air Force facilities. Ed Fratus and Don Johnson - effect of roughness on gage block wringing, flatness of optical flats, height of thin film steps

3. IBM, San Jose, California - Dewayne Sharp - superfinished surfaces (memory discs) present measurement requirements not being met, light scattering measurement of surface roughness

4. Lockheed Missile and Space Company Mr. Carrara - Manager of Dimensiona 1

Metrology Lab. - surface finish instrument calibration

5. Hewlett Packard - Palo Alto, California - Glenn Harreman, Manager of Dimensiona 1 Metrology - calibration of surface instrumentation, measurement of thin film steps, Earl Lindberg, surface instrument designer

6. Dow Chemical Company, Rocky Flats, Col. - John Stover - use of light scattering in measuring surface roughness, Scratch and Dig Standards

7. Ladish Co. - Tri-Clover Division, Kenosha, Wisconsin, Robert L. Nissen, Assistant Vice President - relationship between cleanability of dairy containers and surface roughness

8. Bendix, Automation and Measurement Division, Dayton, Ohio - Fred Witzke, Chief Manufacturer of surface finish measuring instruments

9. Sloan Instrument Company - Manufacturer of surface finish instrumentation

10. Stanford Research Institute, Palo Alto, Cal. - Lou Heynick - electronic surfaces

11. Bel1 Telephone Laboratories, Murray Hi11, N. J. - Dr. Charles Tracy - roughness of the surface of optical fibers for communication use

12. General Motors Corporations, Detroit, Mich. - Robert Lenz - Richard Daskivich ANSI Committee - specialist in surface technology
13. GAR Electroforming Division of Mite Corp. - Eugene Castelzano, Robert Murphy fabrication of precision reference specimens

14. Minnesota Mining and Manufacturing Co., Saint Paul, Minnesota - Peter Banning, John Sulzivan, Tom Voulgares - characterization of manufactured surfaces

15. National Institute for Occupational Safety and Health HEW, Morgantown, W. Va. David Puthoff - Safety of ophthalmic lenses lens failure (a surface related process)

16. Trans - Tech, Inc., Gaithersburg, Md. - Elwood Hokanson - measurement of Ytt.

Gd. Garnet surface roughness

17. Etec Corporation, Hayward, Calif. Jomes Dao, Pres. and Kent Lane, Director of Research - measuring surface topography with Scanning Electron Microscope

18. Pittsburgh Plate Glass, Pittsburgh, $\mathrm{Pa}$. - Nancy Robbins - Roughness of plastic coatings on glass surfaces

19. Federal Products, Providence, Rhode Island - Mohamed Fadl, Director of Research, - the role of surface finish in precision instrumentation

20. Texas Instruments Inc., Dallas, Texas - Ray Hizton - semiconductor surface finish

21. Pennsylvania State University, University Park, Pa. - Prof. Eugene White surface characterization using the Scanning Electron Microscope

22. Bell Laboratories, North American, Mass. - Theaphizos Kubiopulos - surface finish of waveguides

23. Dairy and Food Industries Supply Association, Inc., Washington, D.C. Donald Williams, Technical Director relationship between cleanability of dairy containers and surface roughness

A.3 List of people contacted by phone, at meetings, etc.

1. Bel1 Telephone, Holmdel, N. J. Richard Roca, contact resistance in bloted joints

2. Navel Weapons Center, China Lake, Calif. - Hal Bennett - leading instrument developer for light scattering measurement of surface roughness

3. Rank Industries, England - Robert Sprague, Director of Research, and $D$. Whitehouse - Chief European Competition in field of surface instrumentation

4. Be11 Telephone Labs., Holmde1, N. J.

- Herb Libbin - Semiconductor surfaces

5. The Timken Company, Canton, Ohio W. E. Littman - Manager Metallurgy Research ball bearing surfaces

6. Autometics, Div. of North American Rockwe11, Anaheim, Cal. - Jack HaZz - ruby laser surface measurement 
7. Moore Special Tool Company, Bridgeport, Conn. - Amold W. Young - characterization of surfaces - other parameters

8. The Bendix Corporation, Dayton, Ohio Robert Esken - design of surface finish instrumentation

9. Eric Schnieder, Lake Shore Drive, Chicago, I11. - Improved standards, better characterization of surfaces

10. Sunnen Products - St. Louis, Mo. Wayne $W$. Althen - Characterization of surfaces, better parameters

11. Ehrenreich Photo-Optical Industries, Inc., Garden City, N.Y. - DaZe Freyberg, Product Manager and John Wilson, Chief Engineer-Interference Microscopes and precision reference specimens

12. General Electric Co., Evendale Plant, Ohio - Guy Bezzows, Senior Mfg. Engineer - Measuring finish of machined surfaces

13. Milo Mfg. Co., Union, N. J. - Joseph Mizo, President - Measuring the finish of diamond turned surfaces (1ess than $1 \mu$ inch)

14. Rexnord Corp., Research Development Group, Milwankee, Wis. - Robert Trautman, Senior Engineer - surface of hardened steel, characterization

15. Meditec Inc., (Surgical Implants) Fairlawn, N. J., - Robert Averizl, Vice President, surface finish of hip ball joints and sockets

16. Bendix, Kansas City, Kansas, Pauz Klingsparn - surface inspection

17. Al is Chalmers, Pa., Wizziam Erwin - surface characterization particularly hydro-turbines

18. 3M - St. Paul, Minesota, Clyde Calhoun - instrumentation for measuring asymmetric surfaces

19. Navy Ships Command, Washington, D.C., Tom Martin - relationship between difference amplitude characterization parameters

20. Hughes Aircraft, Oceanside, California, John C. Homocher - laser mirror surface qual ity

21. Oak Ridge National Labs, Oak Ridge, Tenn., H. B. Adams - calibration of special high resolution precision reference specimens

22. Carter Products Research, Cranbury, N. J., Giles Crane-measurement of natural surfaces (teeth, etc.)

23. Dow Chemical Company, Rocky Flats, Colorado, Bizz Utzey - use of optical techniques to measure surface scratches in lenses

24. Allegheny Ludlum Steel, Pittsburgh, Pa., Walter D. EdsalZ - Technical Services Group, roughness of stainless steel plate used in nuclear reactor pool 1 iners, surface measurement

25. Allegheny Ludlum Steel, Leechburg, $\mathrm{Pa}$. , Joseph Bosco - Special Products Vendor Control, refined polishing of steels, surface
26. Bethlehem Steel, Bethlehem, Pa., Charles Stattel, Metallurgist, Robert Moriarity, Metallurgist - finish of automative and chrome plateable steels, surface measurement

27. Republic Steel, Warren, Ohio - Jack Mahaney - Metallurgist, Appliance steel, galvanized products, tin plate automotive steel, surface measurements

28. Chrysler Corporation, Detroit, Michigan - Dan Hommond - Research Senior Scientist, surface finish of automobile components and paintable surfaces 


\section{A.4 Typical Correspondance on Industrial Surface Finish Needs (Names deleted).}

Dr. Russe11 Young

Metrology Division

National Bureau of Standards

Washington, D. C. 20234

Dear Russ:

We have become increasingly interested in the measurement of surface topography in connection with our intense efforts to fabricate very small dielectric waveguides for use in integrated optical circuits. These guides consist of a "filament" of GaAs embedded in a metrix of $A 1_{x} \mathrm{Ga} 1-x \mathrm{As}$ (which has a lower index of refraction than pure GaAs). This structure will support guided modes, the number of which depends on the geometrical and optical parameters chosen.

One of the dominant loss mechanisms encountered in dielectric waveguides of this kind results from the non-flatness of the boundary between the two dielectrics. Such roughness can couple the guided modes with the radiating modes. Thus light initially propagating in the guide will be scattered out resulting in undesirable attenuation.

The scale over which this roughness is important is just the wavelength of the propagating light (in the medium). Theory predicts that the losses from this scattering mechanism are a strong function of the correlation length of the roughness.

We have determined that in the devices we are making, this scattering mechanism is dominating the losses. It is therefore highly desirable to know exactly what the magnitude (rms) of the roughness is as well as its correlation parallel to the surface (i.e. is it random, periodic, etc.). The rms magnitude of the roughness is in most cases less than $100 \AA$. For the worst case of correlation length, the losses will be important down to a rms roughness of less than $20 \AA$.

I have made some diffuse light scattering measurements on dielectric-air interfaces which are believed to have the same topography as the dielectric boundaries which guide the light (but also may scatter $i t$ ). These measurements show that one can apparently detect rms surface roughnesses below $50 \AA$ on the scale we are concerned with, but an inspection of the literature suggests that it may be difficult to obtain any quantitative information. This results from the non-formal distribution of the surface roughness as determined by the spatial character of the diffuse scattering.

If you have any comments or suggestions regarding these problems I would appreciate very much hearing from you.

Best regards,

$\mathrm{Mr} . \mathrm{B}$

$\mathrm{JCT}: \mathrm{SC}$ 
Dear Dr. Young:

I enjoyed very much having the opportunity to meet you and your associates in Pittsburgh last week. I am writing now to request a copy of the report which you described that compares the various optical methods for surface roughness measurement.

As you can well appreciate, the preformance of tapered rolled bearings is critically related to the geometry and texture of the operating surfaces on the raceways and at the rib-roller end contacts. We are well aware of the value of surface texture characterization using stylus tracer instruments and equally aware of the limitations of present methods for analyzing and utilizing surface profile data.

An equally important related problem area is the economical manufacture of the surfaces which are critical to bearing performance. Even if we had adequate tools for the research relating surface microtopography to bearing performance, we still need inexpensive but adequate tools for inspection and process control of surface texture during the manufacturing and assembly of bearings. Ideally such methods should avoid physical contact, be rapid and amenable to automation.

In response to your request, we will describe these needs as they might relate to useful programs at the Bureau of Standards and will also explore the possibility of the "resident intern" type of activity by someone from Company $C$ at the Bureau.

We will look forward to your report on the optical methods and further exchanges of information on surface metrology.

Sincerely yours,

Mr. D

$\mathrm{pj} 1$

Dr. Russe11 D. Young

Dimensional Technology Section

Company $E$

National Bureau of Standards

Washington, D. C. 20234

Dear Dr. Young:

Your article entitled "Surface Microtopography" in the November issue of Physics Today was very interesting. Included was a report of your work on a field emission technique that is being developed to measure surface topography in the $1 \AA$ range. This technique may be useful in rapidly characterizing the surface of highly polished silicon and germanium single crystal slices, which are intended for transistor device applications.

Surface defects including pits, scratches, mounds, stacking faults and also submicroscopic objects have a deleterious effect on the performance of semiconductor devices. Therefore it is desirable to detect these features at the earliest point in the manufacturing procedure and to eliminate those slices which will not have satisfactory electrical characteristics based on surface conditions. Current practice for defect detection requires microscopic examination of a significant area of each polished slice. While this is a time consuming and expensive operation involving subjective decisions by a technician, it is considered necessary in order to achieve the high quality devices required for use by the Be11 System. 
A technique with the capability of providing a quantitative evaluation of single crystal surfaces, especially in an automatic or semiautomatic mode, would be of significant advantage to manufacturers of semiconductor devices. It would be desirable if the system could quickly scan a portion of each slice (about 20 to $40 \mathrm{~mm}^{2}$ in 5 to 10 minutes) and indicate the presence of surface features as well as the contour of the surface. While automatic machine evaluation of the system output would be preferable, interpretation of a series of topographic maps by an operator would be an acceptable alternative.

I would appreciate the opportunity of discussing your system in greater detail with particular emphasis on its applicability for evaluating polished surfaces used for semiconductor applications. In addition, it would be interesting to examine test results covering some typical silicon slices. I am not interested in discussing any restricted of proprietary developments which could not be freely adapted from my own development work for semiconductor applications and freely disclosed to others. Please advise whether the above arrangement is satisfactory so that we can arrange for a meeting at your convenience.

Very truly yours,

$\mathrm{Mr} . \mathrm{F}$

Dr. Russe11 Young

National Bureau of Standards

Washington, D.C. 20234
Company $G$

October 30,1973

Dear Dr. Young:

It was a pleasure to talk to you recently of the telephone concerning the "Topografiner". As I discussed with you on the telephone, we wish to establish a rapid, "on-line" method for inspecting highly polished metal surfaces. We wish to measure not only the rms "background" of the surface profile but also to detect and measure the depths and widths of isolated defects (pits ("digs") and scratches) on an otherwise very smooth background. As you stated on the telephone, the necessity of the high vacuum ( $4 \times 10-10$ Torr) when a tungsten emitter is used practically rules out the Topografiner, in its present form, as an on-line inspection technique. Some rapid surface inspection techniques exist, but depths of isolated digs and scratches cannot be measured. Therefore, I would like to encourage any development effort on your part to move the Topografiner closer to an on-line technique because I feel some segments of industry would welcome such an advance.

Sincerely,

Mr. H

PEK:sf 
B.1 Table of Contents of B46.1-Standard for Surface Texture.

B.2 "Surface Finish, Friction and Wear: The Need for More than One Parameter," D. A. Swyt, NBS Internal Report 73-196, May 3, 1973.

B.3 "Precision Reference Specimens of Surface Roughness: Some Characteristics of the Cali-Block," R. D. Young and R. E. Scire, J. of Research of NBS, Vol. 76C, Jan. 1972.

B.4 Calibration Report - Precision Reference Specimen of Surface Roughness

B.5 "The Public Health Significance of Surface Measurements," Donald H. Williams, Technical Director, Dairy and Food Industries Supply Assoc. Inc. - a statement of their surface measurement problem and its significance, Nov. 8, 1973.

B.6 "Eight Techniques for the Optical Measurement of Surface Roughness," R. D. Young, NBS Internal Report 73-219, May 25, 1973.

B.7 "Surface Microtopography," R. D. Young, Physics Today, Vol. 24, Nov. 1971.

B.8 "The Topografiner: An Instrument for Measuring Surface Microtopography," R. D. Young, J. Ward, and F. Scire, Review of Scientific Instruments, Vol. 43, pp. 999-1011, July 1972 .

B.9 "Evaluation, Revision and Application of the NBS Stylus/Computer System for Surface Roughness Measurement,"E. C. Teague, Technical Note 902. 
2 - CLASSIFICATION OF TERMS AND RATINGS RELATED TO SURFACES . . . . . . . . . . 7

2.1 Surface Texture .................... . . . 7

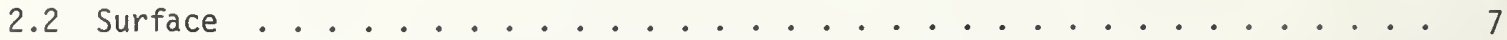

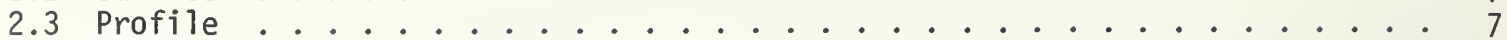

2.4 Center Line . . . . . . . . . . . . . . . . . . 7

2.5 Microinch . . . . . . . . . . . . . . . . . . 8

2.6 Roughness . . . . . . . . . . . . . . . . . . 8

2.7 Waviness . . . . . . . . . . . . . . . . . . 8

2.8 Lay . . . . . . . . . . . . . . . . . . . . 8

2.9 flaws ........................ 8

2.10 Contact Area . . . . . . . . . . . . . . . . . . 9 9

3 - DESIGNATION OF SURFACE CHARACTERISTICS . . . . . . . . . . . . . . 9

3.1 Where to Specify .......................... 9

3.2 Symbols Indicating Direction of Lay . . . . . . . . . . . . . . 9

3.3 Surface Symbol .. . . . . . . . . . . . . . . . . 9

3.4 Application of Symbols and Ratings ................ . . . 9

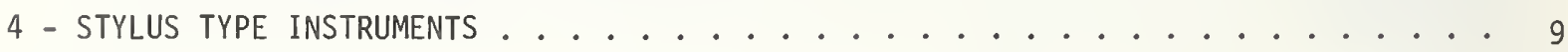

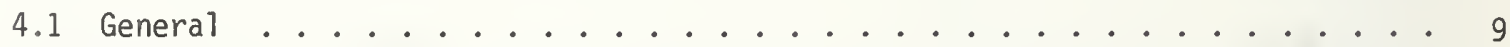

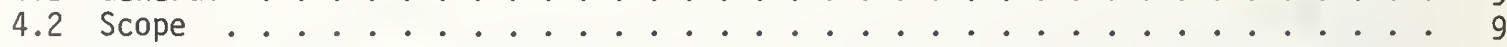

4.3 Purpose . . . . . . . . . . . . . . . . . . . . . . . 9 9

4.4 Tracer Head Characteristics . . . . . . . . . . . . . . . 12

4.5 Traversing Length .................... . . . . 12

4.6 Transducer, Amplifier, and Indicator ............... 13

4.7 Indicating Instrument . . . . . . . . . . . . . . . 13

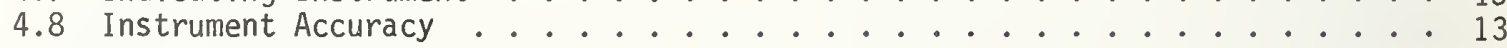

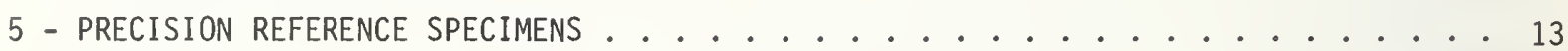

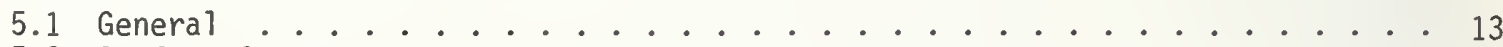

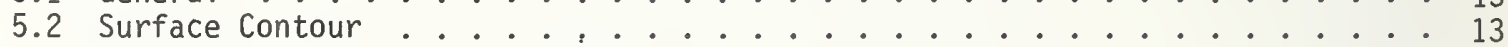

5.3 Material ........................ . . . . . 14

5.4 Accuracy........................ . . . . . 14

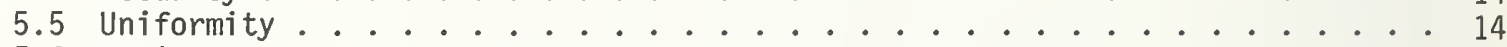

5.6 Rating . . . . . . . . . . . . . . . . . . 14

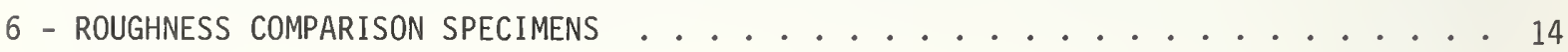

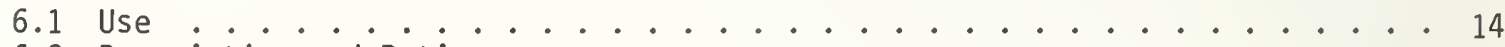

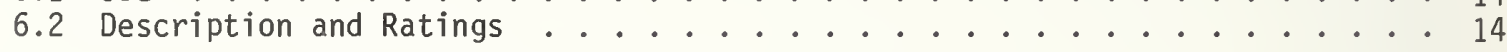

APPENDIX A - SUPPLEMENTARY INFORMATION EXAMPLES . . . . . . . . . . . . 16

A-1 Surface Symbol Proportions . . . . . . . . . . . . . . . 16

A-2 Arithmetical Average .................... . . . 16

A-3 Root Mean Square Average . . . . . . . . . . . . . . . . 16

A-4 Relation of Surface Texture to Tolerances . . . . . . . . . . . . 16

A-5 General Notes for Drawings . . . . . . . . . . . . . . . . 17

A-6 Demonstration of the Application of Surface Roughness Symbols on Drawings . 17

A-7 Control Several 0perations . . . . . . . . . . . . . . . 17

A-8 Flaws . . . . . . . . . . . . . . . . . . . 17

A-9 Waviness Average Height Measurement . . . . . . . . . . . . . . . 18

APPENDIX B - GENERAL NOTES ON USE AND INTERPRETATION OF TRACER INSTRUMENTS . . . . 19

APPENDIX C - USE OF PRECISION REFERENCE SPECIMENS WITH STYLUS INSTRUMENTS . . . . . 22

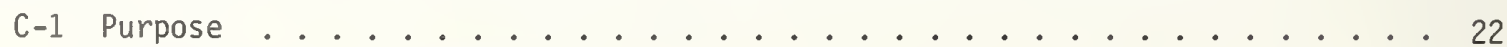

C-2 Checking the Instrument Stylus Radius . . . . . . . . . . . . 22

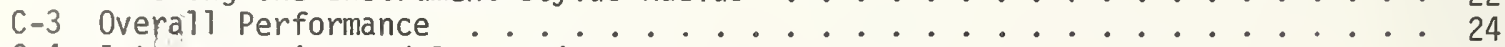

C-4 Interpretation and Precautions . . . . . . . . . . . . . . . 24

APPENDIX D - NOTES ON CONTROL OF SURFACE TEXTURE ............... 25 
Appendix B.2

Surface Finish, Friction and Wear: The Need for More Than One Parameter

Dennis A. Swyt

NBS Internal Report 73-196

ABSTRACT

Surface finish is most commonly described by an arithmetic average (AA) value, often coupled with a description of the process by which the surface is finally formed. Since the insensitivity of the $A A$ parameter to the periodic nature of surface structure is well known, many supplemental "second" parameters have been suggested. This short paper gives an indication of the basis for the insensitivity of the $A A$ parameter to periodic structure and considers briefly some "wavelength-conscious" parameters (e.g., average wavelength and correlation lengths) which may be useful in supplementing the basic AA value for a more complete description of surface finish.

\section{Appendix B.3}

Precision Reference Specimens of Surface Roughness:

Some Characteristics of the Cali-Block

Russel1 D. Young and Fredric E. Scire

Journal of Research of NBS, Vol. 76C, Jan. 1972

ABSTRACT

The distribution of Arithmetic Average values of surface roughness across the 120 and 20 microinch patches of NBS Cali-Block "B" have been measured. It is shown that each distribution can be described in terms of its mean value and standard deviation. The observed systematic distribution of AA values strongly suggests that the user select widely spaced regions at random on the patch when calibrating a roughness measuring instrument. 
Appendix B.4

\section{U.S. DEPARTMENT OF COMMERCE}

NATIONAL BUREAU OF STANDARDS

Apriт 2, 1974

REPORT OF CALIBRATION

$232.08 / 210069$

For: One Precision Roughness Standard

Specimen No. PG-1366

Submitted by: The ...... Corporation

Electrical Components Division

The property of surface roughness in the $5 \mu \mathrm{m}$ (200 microinch) AA range and below is measured at NBS by means of a minicomputer/stylus instrument system. Using an interferometrically measured step the system is calibrated on each value of magnification employed during a measurement. Surface profiles are taken according to the American National Standard B-46.1-1962 using a $0.76 \mathrm{~mm}$. (0.030 inch) cutoff Tength and a $3.80 \mu \mathrm{m}$ (150 $\mu$ in) stylus tip radius. Data is stored in the minicomputer memory employing 12 bit analog to digital

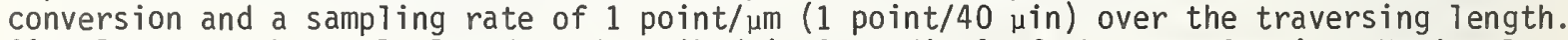
$A A$ values are then calculated as described in Appendix $A$ of the same American National Standard.

A conservative estimate of the systematic error ( $3 \sigma=3$ standard deviations) resulting from stylus pickup nonlinearity, interface hardware, software computations and analog to digital conversion is $1 \%$ for any type of uniform roughness specimen. Other errors are due to electrical and mechanical noise $[3 \sigma=5 \mathrm{~nm}(0.2 \mu \mathrm{in})]$, to the surface finish of the step specmen $[3 \sigma$ of step transfer $=25 \mathrm{~nm}(1 \mu \mathrm{in})]$ and to the interferometric measurements of step heights $[3 \sigma=25 \mathrm{~nm}(1 \mu \mathrm{in})]$. The use of step heights approximately equal to the surface profile peak to valley height then gives a net systematic error for the calibration procedure of $3 \%(3 \sigma)$ or Tess over AA values ranging from $0.25 \mu \mathrm{m}(10 \mu \mathrm{in})$ to the upper Timit of the stylus instrument.

The computed value for the average surface roughness of the area marked $120 \mu$ in $A A$ is $2.94 \mu \mathrm{m}(115.8 \mu \mathrm{in}) \mathrm{AA}$ with an uncertainty of $0.10 \mu \mathrm{m}(4.0 \mu \mathrm{in})$.

The computed value for the average surface roughness of the area marked $20 \mu$ in $A A$ is $0.51 \mu \mathrm{m}$ (20.1 $\mu \mathrm{in})$ AA with an uncertainty of $0.07 \mu \mathrm{m}(2.7 \mu \mathrm{in})$.

The computed value for the average surface roughness of the area marked 12-20 $\mu$ in $A A$ is $0.47 \mu \mathrm{m}(18.6 \mu \mathrm{in}) \mathrm{AA}$ with an uncertainty of $0.16 \mu \mathrm{m}(6.2 \mu \mathrm{in})$.

The uncertainty for this area can be reduced to $0.09 \mu \mathrm{m}(3.6 \mu$ in) with a computed value of $0.4651 \mu \mathrm{m}(18.3 \mu \mathrm{in}) \mathrm{AA}$ if data taken at points 1 and 10 are deleted.

The uncertainties quoted are the sum of the systematic errors just described and the 30 limit estimated from an analysis of data obtained from 3 traverses in each of 10 positions on each of the areas. For reference, a copy of the computer printout of measured values and a diagram of the positions of measurement are included with the report.

Measurements made by
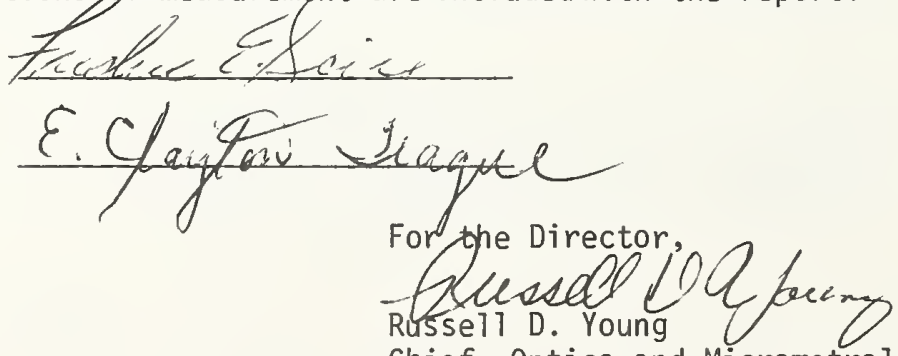

Chief, Optics and Micrometrology Section

Optical Physics Division, IBS 
Appendix B.5

The Public Health Significance of

Surface Measurements

by

Donald H. Williams

Technical Director, Dairy and Food

Industries Supply Association, Inc.

November 8,1973

3-A Sanitary Standards for dairy processing equipment provide criteria for the cleanability of product contact surfaces, and for product protection. The fabrication section of a 3-A Standard requires that product contact surfaces be at least as smooth as a \#4 mill finish properly applied to stainless steel sheets.

Number 4 is a ground finish. A surface polished with 150 grit silicon carbide abrasive is deemed to be in compliance with the finish criterion. There is some interest in using a cold rolled or $2 B$ finish if selected sheets can be pit-free. There is some suggestion that a $2 \mathrm{~B}$ finish is smoother than a \#4, but they cannot be directly compared since the 2B is not a polished surface.

A method is needed to quantify consistently the surface of stainless steel, whether cold rolled, \#4 polished, or cast. Cleanability and sanitation are associated empirically with smoothness. Acceptable surfaces are based on the visual examination in comparison with a known or authentic \#4 finish, yet there is lack of uniformity in \#4 among polishers. As polishing belts wear, there is variation in the resulting surface.

Millions of dollars worth of equipment are purchased by the dairy processing industry. By far the majority of such equipment today--especially in the fluid milk industry--is built to meet $3-A$ Standards which are generally recognized by regulatory sanitarians and health officers.

The volume of fluid milk products and ice cream which are processed in "non-3-A equipment" is insignificant. The acceptance of surface finish for dairy equipment is therefore of monumental significance. A convenient tool or index for uniformly determining or characterizing surface finish of stainless steel would be of great value to the dairy and food industries.

Of real significance is the growing use of 3-A criteria in food industries other than dairy. A separate new 3-A program has been developed for the egg products industry, and 3-A criteria are widely used by most other food industries in writing equipment specifications for meat, brewing, beverage, frozen foods, to name a few. A means for evaluating surface finish, therefore, has momentous importance to the sanitation of food processing

Appendix B.6

Eight Techniques for the Optical Measurement of Surface Roughness

Russel1 D. Young

NBS Internal Report 73-219, May 1973

ABSTRACT

The need for a fast, on line, non-destructive technique for measuring surface roughness has recently accelerated the decade long development of optical methods. It is anticipated that these new techniques will add a new dimension to the surface roughness measurement system which may require an appropriate NBS response. In order to formulate this response, the eight optical techniques which have been identified are briefly described and are summarized and compared in Table 1.

It is concluded that model deficiencies, questionable theoretical bases, as well as physical and analytical limitations cast serious doubt on the present accuracy of these techniques for absolute measurements. Optical Techniques seem more suitable for comparison measurements, i.e., measurement after appropriate calibration using surfaces which have been measured using other techniques. Thus, it is concluded that the most appropriate NBS re- 
sponse to the increased use of optical techniques it to concentrate our limited resources on developing much improved instruments such as the Topografiner and traditional stylus instruments so that highly refined optical surfaces can be measured and their surface parameters determined accurately.

Appendix B.7

\author{
Surface Microtopography \\ Russe11 D. Young \\ Physics Today, Vol. 24 \\ November, 1971
}

\begin{abstract}
The growing field of surface science would benefit considerably from measurement of surface microtopography down to the atomic level. A brief review is presented of several instruments used to quantitatively characterize the surface microtopography of metallic surfaces. Techniques are discussed for employing the transmission electron microscope, the scanning electron microscope, the optical interference microscope and an engineering profile measuring instrument to measure surfaces suitable for surface science experiments. In addition a new non-contacting instrument which is presently under development will be described. It is concluded that several techniques are presently available for detecting single atom steps on single-crystal surfaces.
\end{abstract}

Appendix B.8

The Topografiner: An Instrument for Measuring Surface Microtopography

Russell Young, John Ward, and Fredric Scire

The Review of Scientific Instruments

March 29, 1972

\begin{abstract}
A noncontacting instrument for measuring the microtopography of metallic surface has been developed to the point where the feasibility of constructing a prototype instrument has been demonstrated. The resolution of the preprototype unit is $30 \AA$ perpendicular to the surface and $4000 \AA$ in the plane of the surface. Inherent noise in the perpendicular direction corresponds to $3 \AA$, one atomic layer. By using a typical field emitter with radius of $100 \AA$, an ultimate limit of $200 \AA$ would be expected for the horizontal resolution. Topographic maps of an infrared diffraction grating have been measured in order to demonstrate the performance of the instrument in measuring a well characterized surface. The instrument has been shown to conform to the Fowler-Nordheim description of field emission while spaced at the usual operating distances for the surface. When moved to within $30 \AA$ of the surface, its performance is compatible with Simmons' theory of MVM tunneling. In the MVM mode, the instrument is capable of performing a noncontacting measurement of the position of a surface to within about $3 \AA$. The instrument can be used in surface science experiments to study the density of single and multiple atom steps on single crystal surfaces, adsorption of gases, and processes involving electronic excitations at surfaces.
\end{abstract}


Appendix B.9

Evaluation, Revision and Application of the NBS Stylus/Computer

System for Surface Roughness Measurement

E. Clayton Teague

NBS Technical Note 902

\section{ABSTRACT}

This report describes in detail the hardware and software used at NBS to implement on a stylus instrument/minicomputer system the process of calibrating the system with an interferometrically measured step and the calculation of important characterizations of surface profiles. The characterizations of a profile which may be calculated include the Arithmetic Average value, the mean square value, the amplitude density function, the autocorrelation function and the average wavelength. The report also includes a statistical evaluation, using empirical and analytical techniques, of the calibration procedure's long term stability. 
NBS-114A (REV. 7.73)

\begin{tabular}{|c|c|c|}
\hline \begin{tabular}{c|c} 
U.S. DEPT. OF COMM. & 1. PUBLICATION OR REPORT NO. \\
BIBLIOGRAPHIC DATA & NBSIR 75-927 \\
SHEET &
\end{tabular} & $\begin{array}{l}\text { 2. Gov't Accession } \\
\text { No. }\end{array}$ & 3. Recipient's Accession No. \\
\hline \multicolumn{2}{|l|}{ 4. TITLE AND SUBTITLE } & 5. Publication Date \\
\hline \multicolumn{2}{|c|}{ The National Measurement System for Surface Finish } & 6. Performing Organization Code \\
\hline \multicolumn{2}{|l|}{ Russell D. Young } & 8. Performing Organ. Report No. \\
\hline \multicolumn{2}{|l|}{$\begin{array}{l}\text { 9. PERFORMING ORGANIZATION NAME AND ADDRESS } \\
\text { NATIONAL BUREAU OF STANDARDS } \\
\text { DEPARTMENT OF COMMERCE } \\
\text { WASHINGTON, D.C. } 20234\end{array}$} & \begin{tabular}{|l} 
10. Project/Task/Work Unit No. \\
11. Contract/Grant No.
\end{tabular} \\
\hline \multirow{2}{*}{\multicolumn{2}{|c|}{ 12. Sponsoring Organization Name and Complete Address (Street, City, State, ZIP) }} & $\begin{array}{l}\text { 13. Type of Report \& Period } \\
\text { Covered }\end{array}$ \\
\hline & & 14. Sponsoring Agency Code \\
\hline
\end{tabular}

15. SUPPLEMENTARY NOTES

16. ABSTRACT (A 200-word or less factual summary of most significant information. If document includes a significant bibliography or literature survey, mention it here.)

NBS has conducted a study of the National Measurement System for Surface Finish. The proposed system model is discussed including the role of standards committees, instrument manufacturers and measurement users. The econamic dimensions of the measurements impact areas and the technological base fram which new measurement technology springs is described.

17. KEY WORDS (six to twelve entries; alphabetical order; capitalize only the first letter of the first key word unless a proper name; separated by semicolons)

Surface, Surface Finish, Surface Roughness, Measurement, Technology Assessment, Economic Factors.

18. AVAILABILITY Unlimited

XX For Official Distribution. Do Not Release to NTIS

Order From Sup. of Doc., U.S. Government Printing Office

Washington, D.C. 20402, SD Cat. No. C13

Order From National Technical Information Service (NTIS) Springfield, Virginia 22151

\begin{tabular}{|l|l|}
\hline $\begin{array}{l}\text { 19. SECURITY CLASS } \\
\text { (THIS REPURT) }\end{array}$ & 21. NO. OF PAGES \\
UNCL ASSIFIED & 22. Price \\
\hline $\begin{array}{l}\text { 20. SECURITY CLASS } \\
\text { (THIS PAGE) }\end{array}$ & \\
UNCLASSIFIED & USCOMM-DC 29042-P74
\end{tabular}




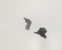


